$1 \quad$ XRD-based ${ }^{40} \mathrm{Ar} /{ }^{39} \mathrm{Ar}$ age correction for fine-grained illite, with

\title{
(northern Mexico)
}

4 Elisa Fitz-Díaz ${ }^{1,2}$, Chris Hall ${ }^{2}$ and Ben van der Pluijm ${ }^{2}$

5 Instituto de Geología, Universidad Nacional Autónoma de México Ciudad Universitaria, 04510,

6 México, D. F. elisaf@geologia.unam.mx

$7 \quad{ }^{2}$ Department of Earth \& Environmental Sciences, University of Michigan, 1100 North University

8 Ave., Ann Arbor, MI 48109-1005. cmhall@umich.edu, vdpluijm@umich.edu

9 ABSTRACT

10 Due to their minute size, ${ }^{40} \mathrm{Ar} /{ }^{39} \mathrm{Ar}$ analysis of illite faces significant analytical challenges,

11 including mineral characterization and, especially, effects of grain size and crystallography on

$12{ }^{39} \mathrm{Ar}$ recoil. Quantifying the effects of ${ }^{39} \mathrm{Ar}$ recoil requires the use of sample vacuum

13 encapsulation during irradiation, which permits the measurement of the fraction of recoiled ${ }^{39} \mathrm{Ar}$

14 as well as the ${ }^{39} \mathrm{Ar}$ and ${ }^{40} \mathrm{Ar} *$ retained within illite crystals that are released during step heating.

15 Total-Gas Ages (TGA) are calculated by using both recoiled and retained argon, which is

16 functionally equivalent to K-Ar ages, while Retention Ages (RA) only involve retained Ar in the

17 crystal. Natural applications have shown that TGA fits stratigraphic constraints of geological

18 processes when the average illite crystallite thickness (ICT) is smaller than $10 \mathrm{~nm}$, and that RA

19 matches these constraints for ICTs larger than $50 \mathrm{~nm}$. We propose a new age correction method

20 that takes into account the average ICT and corresponding recoiled ${ }^{39} \mathrm{Ar}$ for a sample, with X-

21 Ray Corrected Ages (XCA) lying between Total-Gas and Retention ages depending on ICT. This 
22 correction is particularly useful in samples containing authigenic illite formed in the anchizone,

23 with typical ICT values between 10 and $50 \mathrm{~nm}$.

24 In three samples containing authigenic illite from Cretaceous carbonates in the Monterrey

25 Salient in northern Mexico, there is a range in TGAs among the different size-fractions of 46-49,

26 36-43 and 40-52 Ma, while RAs range from 54-64, 47-52 and 53-54 Ma, respectively. XCA

27 calculations produce tighter age ranges for these samples of 52.5-56, 45.5-48.5 and 49-52.5 Ma,

28 respectively. In an apparent age vs ICT or \%2M1illite plot, authigenic illite grains show a slope

29 that is in general slightly positive for TGA, slightly negative for RA, but close to zero for XCA,

30 with thinner crystallites showing more dispersion than thicker ones. In order to test if dispersion

31 is due to a different formation history or the result of retention capability, degassing spectra were

32 modeled for site XCA averages and overall XCA average. Modeling shows that local site age

33 average best match the measured spectra, instead of a global average age, indicating that illite

34 growth reflects local deformation, and is not the result of regional metamorphism. Modeling also

35 shows that Ar-degassing spectra are very sensitive to grain size, such that age interpretation

36 based on Ar-plateaus is meaningless for most fine-grained clays.

38 KEYWORDS: Ar-Ar dating, illite, XRD, crystallinity

\section{INTRODUCTION}

$40 \quad{ }^{40} \mathrm{Ar} /{ }^{39} \mathrm{Ar}$ illite dating is commonly used to analyze the timing of various geological

41 processes in the upper crust, including diagenesis and hydrocarbon formation (Pevear, 1999;

42 Dong et al., 2000; Clauer et al., 2011; 2012), low grade metamorphism (Dong et al., 1997;

43 Merriman and Peacor, 1999; Verdel et al., 2011), epithermal ore formation (Hall et al., 1997 and

44 2000), faulting (e.g., van der Pluijm et al., 2001; Solum and van der Pluijm, 2005; Haines and 
45 van der Pluijm, 2008; Osborn et al., 2014), and folding (Fitz-Díaz and van der Pluijm, 2013;

46 Fitz-Díaz et al., 2014a). Illite is one of the few K-bearing minerals that form under diagenetic

47 and anchizonal conditions (Fig. 1a) and has the capacity of retaining radiogenic argon $\left({ }^{40} \mathrm{Ar}^{*}\right)$ in

48 its structure after natural recoil (i.e., ${ }^{40} \mathrm{Ar} * \mathrm{~nm}$-scale displacement during ${ }^{40} \mathrm{~K}$ spontaneous

49 radioactive decay, Zimmermann and Odin, 1982; Szczerba et al., 2015) at low temperature

50 (Hassanipak and Wampler, 1996; Clauer et al., 1997; Sletten and Onsttot, 1998).

$51 \quad{ }^{40} \mathrm{Ar} * / 39$ Ar dating is a variant of the K-Ar dating method that allows for the analysis of small

52 amount of samples with high precision (van der Pluijm et al., 2001; Clauer, 2012). The K-Ar

53 dating technique is based on the decay of the rare ${ }^{40} \mathrm{~K}$ isotope into ${ }^{40} \mathrm{Ar}$ and radiogenic ${ }^{40} \mathrm{Ar}$ is

54 typically designated ${ }^{40} \mathrm{Ar} *$. Such a transformation involves a low energy process, known as

55 electron capture, that retains most of the ${ }^{40} \mathrm{Ar} *$ in the parent ${ }^{40} \mathrm{~K}$ site after decay (Fig. 1,

56 Beckinsale and Gale, 1969). Recently, Szczerba et al. (2015) demonstrated, using molecular

57 dynamics simulations, that some dislocation of ${ }^{40} \mathrm{Ar} *$ is possible within illite due to the decay of

$58{ }^{40} \mathrm{~K}$, but the net loss is expected to be very small for all but the smallest of illite particles

$59\left(<0.02 \mu \mathrm{m}\right.$ in diameter and less than five illite fundamental layers). For ${ }^{40} \mathrm{Ar} *{ }^{39} \mathrm{Ar}$ dating, the $\mathrm{K}$

60 content is estimated by producing ${ }^{39} \mathrm{Ar}$ in a nuclear reactor using the fast neutron reaction ${ }^{39} \mathrm{~K}$

61 (n,p) ${ }^{39} \operatorname{Ar}$ (Merrihue and Turner, 1966). Assuming a constant ${ }^{39} \mathrm{~K} /{ }^{40} \mathrm{~K}$ ratio, one can then use

$62{ }^{39} \mathrm{Ar}$ as a proxy for ${ }^{40} \mathrm{~K}$ (McDougall and Harrison, 1999). The ${ }^{40} \mathrm{Ar} /{ }^{39} \mathrm{Ar}$ age equation is given by:

$63 t=\frac{1}{\lambda} \ln \left(1+J \frac{{ }^{40} A r *}{{ }^{39} A r}\right)$

64 where $\lambda$ is the total decay constant for ${ }^{40} \mathrm{~K}$ and $J$ is a conversion constant determined by

65 analyzing mineral standards of known K-Ar age, as neutron flux monitors.

66

In fine-grained samples, such as illite, many studies have shown that the effects of ${ }^{39} \mathrm{Ar}$

67 recoil can be significant (Turner and Codogan, 1974; Halliday, 1974; Hall, 2014). Onstott et al. 
68 (1995) calculated a mean recoil range of $162 \mathrm{~nm}$ for the reaction ${ }^{39} \mathrm{~K}$ (n, p) $-{ }^{39} \mathrm{Ar}$, which explains

69 why small flake-shaped crystallites of illite (Fig. 1b), often smaller than $2000 \mathrm{~nm}$ in diameter and

$70 \quad 30 \mathrm{~nm}$ in thickness, lose significant amounts of ${ }^{39} \mathrm{Ar}$ during irradiation. Seidemann (1976)

71 devised a method of vacuum encapsulation of fine-grained samples during irradiation, and after

72 opening the sample capsule within the fusion system (i.e., a vacuum line where the sample is

73 heated for thermal degassing) to directly measure the release of ${ }^{39} \mathrm{Ar}$ that occurred during neutron

74 irradiation. The technique has since been applied with considerable success by several

75 laboratories (e.g., Hess and Lippolt, 1986; Foland et al., 1992; Smith et al., 1993), and has been

76 routinely used at the Argon Geochronology Laboratory of the University of Michigan since the

77 mid-1990's.

78 Total-Gas Ages (TGA, Fig. 2a) are calculated from Equation 1 by using both recoiled and 79 retained argon after breaking the silica capsule, while Retention Ages (RA, Fig. 2b) only involve 80 retained Ar in the crystal (Dong et al., 1995). The Total-Gas Age model considers that K is

81 absent in the two exposed half interlayers (top and bottom, Fig. 2a) and that ${ }^{39} \mathrm{Ar}$ in the recoil

82 fraction has escaped from the interlayers (gray area, Fig. 2a) during neutron irradiation. Since the

83 unbound or exposed half interlayers (i.e., K bearing surface bounding TOT fundamental particles

84 of illite, Fig. 1) do not contribute to the total ${ }^{39}$ Ar inventory, all of the ${ }^{39}$ Ar measured, both

85 retained and recoiled, is included in the age calculation, hence the name Total Gas Age. On the

86 other hand, the retention age model considers that $\mathrm{K}$ is present in all non-retentive sites (two

87 exposed half layers, smectite layers and dislocations, Aronson and Douthitt, 1986, Fig. 2b), and

88 that ${ }^{39} \mathrm{Ar}$ in the recoil fraction $\left(f_{\text {recoil }}\right)$ comes from such layers. Since radiogenic ${ }^{40} \mathrm{Ar} *$ would have

89 already escaped the exposed interlayers, that component of the total ${ }^{39}$ Ar inventory should be

90 omitted from the age calculation. 
92 stratigraphic constraints of geological processes when illite crystallite thickness (ICT, see

93 Kübler, 1968; Eberl and Velde, 1989) are smaller than 10-15 nm (e.g., Hnat and van der Pluijm,

94 2014), while RAs better match stratigraphic constraints when illite crystallites are thicker (e.g.,

95 Dong et al., 1995, 1997, 2000; Hall et al., 1997; Verdel et al., 2011; Fitz-Díaz et al., 2014a, Fig.

96 2a-b). Illite crystals with illite crystallite thickness $>50 \mathrm{~nm}$ tend to have total gas and retention

97 ages that are close to each other, and when crystallites are larger than $150 \mathrm{~nm}$ the ages are

98 identical within the analytical error (Hall, 2014). However, samples with illite crystallite

99 thickness between 10 and $50 \mathrm{~nm}$ might have intermediate ages between TGAs and RAs, but

100 there is currently no quantitative method to calculate such an age, which is the focus of this

101 paper.

102

The XRD-derived illite crystallinity (IC) provides a measure of average illite crystallite

103 thickness $(I C T)$ in $\mathrm{nm}$, here considered as the average number of TOT fundamental units of illite,

104 which are $1 \mathrm{~nm}$ thick (Fig. 1). The average number of TOT layers or ICT (in nm) in a sample

105 also contains the same number of K-bearing interlayers. ${ }^{40} \mathrm{Ar} /{ }^{39} \mathrm{Ar}$ step-heating analysis gives the

106 average fraction of recoil in the samples. This is the fraction of ${ }^{39}$ Ar released after breaking the

107 sample quartz capsule and prior to heating and this recoil fraction does not include Ar retained

108 within illite crystals. According to Dong et al. (1995), this can be visualized as an average

109 number of Ar-retentive TOT interlayers, here is indicated as $n_{a}$, where $n_{a}=1 / f_{\text {recoil }}$. The average

110 recoil distance in silicates for ${ }^{39} \mathrm{Ar}$ is $162 \mathrm{~nm}$, or roughly the equivalent of 162 TOT layers. ${ }^{39} \mathrm{Ar}$

111 concentration can be assumed to have been thoroughly homogenized within illite crystals, so

$112{ }^{39}$ Ar will only be retained if the recoiled atom ends up in a bound interlayer (Fig. 2c). See the 113 methods section for further discussion. 
115 that was formed during a single deformation event, thereby allowing us to characterize the

116 effects of ICT on ${ }^{40} \mathrm{Ar} /{ }^{39} \mathrm{Ar}$ illite age. XRD studies were performed on four clay-size-fractions

$117(1-2,1-0.2,0.2-0.05$, and $<0.05 \mu \mathrm{m})$ of three illite-dominated samples. Mineralogical

118 composition of the samples, as well as crystallographic properties such as illite crystallite

119 thickness (ICT) and polytype quantification were obtained. We tested our new XCA calculation

120 with synthetic age spectra based on Monte Carlo simulation outlined in Hall et al. (1997, 2000),

121 which successfully reproduces experimental age spectral patterns. By comparing experimental

122 and modeled degassing patterns, we show that our new age correction method matches

123 theoretical prediction. Our results have implications in understanding the effect of grain size on

124 Ar-Ar age interpretations, and on the meaning of (absent) plateaus in illite degassing spectra.

2. GEOLOGICAL SETTING

128 sector of the Mexican Fold-Thrust Belt in northeastern Mexico (Padilla y Sánchez, 1982;

129 Campa-Uranga, 1983; Chávez-Cabello et al., 2005). The Mexican Fold-Thrust Belt (MFTB) is

130 mostly a thin-skinned thrust belt that involves a thick package of Cretaceous carbonates (Eguiluz

131 de Antuñano et al., 1999; Fitz-Díaz et al., 2011). Lateral and vertical facies variations of

132 carbonates exert controls on deformation styles, which are fold-dominated in stratified deep-

133 water carbonate successions and thrust-dominated in massive, shallow-water carbonate platforms

134 (Fitz-Díaz et al., 2012). Shortening in the MFTB was progressive and episodic from west to east

135 and occurred in a time span between 86 and 43 Ma in central Mexico (Fitz-Díaz et al., 2014a). 
136 In the Monterrey Salient, the sedimentary cover is constituted by a horizon of Middle Jurassic

137 evaporites, which is hundreds meters of thick (Minas Viejas Fm.) and carbonates (Zuloaga Fm.),

138 covered by Late Jurassic terrigenous units (La Casita and Taraises formations). These, in turn,

139 are overlain by a succession of thickly bedded shallow-water Cretaceous carbonates interbedded

140 with bentonitic shale (Cupido, La Peña and Aurora fms.), covered by Late Cretaceous

141 terrigenous units (Agua Nueva, San Felipe and Mendez fms. Fig. 3b-c). The successions show a

142 thin-skinned deformation style, dominated by a train of upright, symmetrical, km-scale, buckle

143 folds, detached above a thick horizon of evaporites (Fig. 3c, Padilla y Sánchez, 1982; Carmelo

144 1998; Chávez-Cabello et al., 2005). Balanced cross-section analysis provided an estimate of a

145 minimum of $33 \%$ of horizontal shortening by folding (Marrett and Aranda, 1999). According to

146 physical models on folding of carbonate sequences above a very weak detachment, deformation

147 is likely synchronous in all folds along the train (e.g., Dixon, 2004). Therefore, we expect that

148 illite formation is contemporaneous in both limbs of a fold (Fitz-Díaz and van der Pluijm, 2013),

149 which we test by dating two limbs in two folds and a hinge of a fold in between. We collected

150 samples of bentonitic shale in three folds, Sample 1 on the forelimb of the Los Muertos

151 Anticline, in the northern front of the Monterrey Salient; Sample 2 in the hinge of Los Nuncios

152 Anticline to the south; and Sample 3 in the backlimb of the Clavelillas Anticline, farther south

153 (Fig. 3c and 4). The timing of deformation in the area can be constrained from the age of

154 deposition of syn-tectonic units in La Popa Basin (foreland basin to the north of the Monterrey

155 Salient, Fig, 3a), indicating that fold-related uplifts in the area occurred in the Paleogene

156 (Lawton et al., 2009; Gray and Lawton, 2011).

157 Samples were collected from strongly sheared shale layers associated with a single event 158 of folding (Fig. 4a-b). SEM and XRD analysis in this study show that samples consist mostly of 
159 illite, with minor amounts of calcite, quartz, kaolinite and iron oxides. Illite crystals are very

160 homogeneous in size (few microns in diameter), and show a strong alignment with bedding-

161 parallel, shear-related foliation. The fact that almost all illite grains show similar size and

162 morphology (lath shape), and the absence of overgrowth of hairy shaped alteration illite,

163 suggests only one generation of illite present in the sample (Fig. 4c-e).

\section{METHOD}

Based on field considerations, such as the evidence of only one generation of folding and no

167 secondary alteration in the samples, we centered our analysis on samples 1,2 and 3 in the

168 forelimb, hinge and backlimb of a train of folds in the northernmost front of the Monterrey

169 Salient in Aptian limestone successions, as shown in Figure 3. We collected 200 grams of shale

170 sample, from which four grain-size fractions were separated by centrifugation, in order to

171 concentrate illite from other phases in the sample. Illite concentrates were characterized with

$172 \mathrm{XRD}$, dated with the Ar-Ar vacuum-encapsulation method (Dong et al., 1995; van der Pluijm et

173 al., 2001). We obtained illite crystallinity (ICT), fraction of recoil, traditional Total Gas Ages

174 (TGA) and Retention Ages (RA), and determined corrected ages (XCA) from our new method 175 that were tested with Monte Carlo simulations.

\subsection{Clay Characterization}

Illite concentration included rock crushing, dispersion of powder in de-ionized water in

179 an ultrasonic bath, separation of four clay size-fractions $(<0.05 \mu \mathrm{m}$, fine; 0.05-0. $2 \mu \mathrm{m}$, medium-

180 fine; 0.2-1 $\mu \mathrm{m}$-medium-coarse; and 1-2 $\mu \mathrm{m}$, coarse) by centrifugation, and sample drying.

181 Randomly oriented preparations of the $<2 \mu \mathrm{m}$ clay size-fraction samples were created to 
182 characterize the mineralogy by scanning from $2^{\circ}-50^{\circ} 2 \theta(\mathrm{Cu} \mathrm{K} \alpha)$ at a rate of $1^{\circ}$ per minute,

183 which verified that no other phases containing potassium or hydrogen are present in the clay

184 size-fractions. Oriented clay slurry mounts with a concentration of at least $4 \mathrm{mg} / \mathrm{cm}^{2}$ of the five

185 size-fractions were prepared by sedimentation onto glass slides and measured from 2 to $30^{\circ} 2 \theta$

186 under air-dried and glycolated conditions. Air-dried samples were measured at a rate of $1 \% \mathrm{~min}$,

187 while XRD measurements of glycolated preparations were carried at a speed of $1 \% 20$ seconds.

188 Mineralogical identification, the presence of discrete illite and smectite, interlayered with illite

189 and/or chlorite, was identified by comparing XRD patterns in air-dried and glycolated

190 preparations as described by Moore and Reynolds (1997), see Appendix 1.

191 We measured the illite crystallinity (IC) or Kübler index (Kübler 1967) of clays, which is

192 a measure of the ordering/thickness of illite crystallites, but has also been attributed to the

193 temperature of formation (Kübler, 1968). The illite crystallinity (IC) corresponds to the full

194 width ( $\Delta 2 \theta$ angle) at the half maximum of the 001 basal reflection of the $10 \AA$ or $1 \mathrm{~nm}$ peak of

195 illite in the XRD pattern of an oriented preparation. Calibration of the IC followed the procedure

196 of Warr and Rice (1994). With calibrated IC and using the Scherrer equation we obtain the illite

197 crystallite thickness (Patterson, 1939), see Figure 5a.

198 The proportions of illite polytypes, $2 \mathrm{M}_{1}$ (detrital) and $1 \mathrm{M}_{\mathrm{d}}$ (authigenic), in the samples

199 (Fig. 5b) were determined by comparing XRD patterns measured in randomly-oriented powder

200 samples with high-resolution patterns measured on standards. XRD patterns of Owl Creek

201 muscovite clay-size powder is a proxy for $2 \mathrm{M}_{1}$ (detrital) illite, and the $1 \mathrm{Mt}_{1}$ standard of the Clay

202 Mineralogical Society is a proxy for $1 \mathrm{M}_{\mathrm{d}}$ (authigenic) illite (Haines and van der Pluijm, 2008).

203 The patterns from end-member standards are numerically mixed and compared in an Excel

204 spreadsheet, and best-matched with measured patterns. This allows for the estimation of the ratio 
205 of detrital to authigenic illite for different size-fractions within a few \% (Ylagan et al., 2002;

206 Solum and van der Pluijm, 2007, Appendix 2).

207 Scanning Electron Microscopy (SEM) offered high-resolution imaging of sample fabrics.

208 Minerals and their textural expression were studied in rock-chips coated with gold and analyzed

209 in the secondary electron mode; mineral phases were analyzed by Energy Dispersive X-ray

210 Spectroscopy (EDS). SEM images showed the distribution of large clay grains (i.e., pieces of

211 which could be present in the clay size-fractions analyzed) with respect to cleavage (Fig. 4c-e).

\section{2 ${ }^{40} \mathrm{Ar} *{ }^{39} \mathrm{Ar}$ Illite Dating}

Around 10 milligrams of illite concentrates of different grain size-fractions were mixed

215 with deionized water in $2 \mathrm{~mL}$ centrifuge tubes, and centrifuged at 10,000 rpm for 30 minutes, in

216 order to concentrate illite particles in a condensed pellet. After drying the illite pellets were cut in

217 tiny, $0.5-1 \mathrm{mg}$ cubes that were then placed inside thin silica tubes ( $1 \mathrm{~mm}$ inside diameter and 5

$218 \mathrm{~cm}$ long). Each tube was attached to a vacuum line, atmospheric air was pumped out while the

219 sample region was immersed water and then the tube was necked and fire cut (Hall, 2014). The

220 vacuum encapsulated sample was packed and sent to the McMaster Nuclear Reactor for neutron

221 bombarding for a duration of $90 \mathrm{MWh}$. After irradiation the silica capsule is placed in a glass

222 vacuum line connected to a VG1200S mass spectrometer. The capsule was broken with a steel

223 ball that was manipulated with a magnet, with the ${ }^{39} \mathrm{Ar}$ released accounting for the recoiled

224 fraction $\left(f_{\text {recoil }}\right)$. Then the sample was step heated with a $5 \mathrm{~W}$ continuous Ar-ion laser. Total Gas

225 Ages (TGA) include recoiled and retained (released during heating) ${ }^{39} \mathrm{Ar}$ in the age calculation

226 (see eq. 1) while model-based retention ages (RA) only consider retained Ar within the illite

227 structure (Dong et al., 1995). 
The new XRD correction ages, or XCA, consider an illite stack comprised of a number of

229 TOT layers, which is equivalent to the illite crystallite thickness (ICT in nm, Figs. 1 and 2c).

230 Non-retentive interlayers within the stack (i. e. when $n_{a}<I C T$ ) are assumed to possess $\mathrm{K}$ in the

231 same concentrations as internal retentive layers. As ICT approaches $n_{a}$, the correction method

232 approaches the TGA. Thus, $n_{a}, I C T$ and TGA are used to determine XCA according to the

233 equation below (Fig. 2c).

$234 \quad \boldsymbol{X C A}=\left(\frac{\boldsymbol{T G A} \times(I C T-1) \times n_{a}}{\left(n_{a}-1\right) \times I C T}\right)$

235 where $\boldsymbol{T G A}=\boldsymbol{e}^{\boldsymbol{\lambda} * \boldsymbol{T} \boldsymbol{G A}}-\mathbf{1}$ and $\boldsymbol{T G A}$ is proportional to ${ }^{40} \mathrm{Ar}^{*} /^{40} \mathrm{~K}$.

236 XCA error is a weighted average with respect to RA's and TGA's analytical errors.

237 Illite dating was applied to the samples from the Monterrey area in northern Mexico. This

238 method is based on the fact that $2 \mathrm{M}_{1}$ (detrital) illite is concentrated in coarser size-fractions,

239 while much finer $1 \mathrm{M}_{\mathrm{d}}$ illite grew during subsequent diagenesis or deformation. In order to

240 examine provenance, we plot Ar-illite ages vs. $\% 2 \mathrm{M}_{1}$ (detrital) illite of multiple grain size-

241 fractions from a single sample and calculate the ages at 0 and $100 \%$ of $2 \mathrm{M}_{1}$ illite by using York

242 regression (Mahon, 1996). Intersection at $100 \%$ of $2 \mathrm{M}_{1}$ corresponds to the detrital illite age,

243 while intersection at $0 \%$ of $2 \mathrm{M}_{1}$ is the age of authigenic illite. York regression considers standard

244 errors in both Ar ages and composition, of which the latter are much greater, resulting in

245 extrapolated ages with errors that are larger than those from individual Ar ages. Note that

246 negative slopes might reflect Oswald ripening growth of illite (Verdel et al., 2012), while

247 horizontal trends imply that all illite size-fractions and polytypes were (trans)formed at

248 approximately the same time (Fitz-Díaz et al., 2014a). 


\subsection{Monte Carlo argon diffusion model}

In order to model expected ages for studied samples, we use results of a random walk

252 Monte Carlo simulation that was outlined in Hall et al. (1997) and Hall et al. (2000). In the latter

253 study, Ar atoms were individually positioned randomly on a hexagonal grid that was used to

254 mimic the geometry of expected K or Ar locations within illite interlayers. The grain size used

255 has a diameter of 200 unit cells and the simulation was repeated 100,000 times to approximate a

256 uniform initial Ar concentration profile within the interlayer. For each time step, an atom could

257 attempt to move in one of 8 directions, either vertically up or down into a bounding TOT layer,

258 or alternatively, along one of 6 possible directions along the interlayer hexagonal grid (Fig. 6). In

259 the case of all ${ }^{40} \mathrm{Ar} *$ atoms and those ${ }^{39} \mathrm{Ar}$ atoms that are bound by at least two TOT layers in

260 both vertical directions, any attempt to move through a TOT layer is unsuccessful and therefore

261 transport is solely in the plane of the interlayer. Such Ar atoms can only exit the crystal by

262 moving beyond the edge of the hexagonal grid. ${ }^{39} \mathrm{Ar}$ atoms fitting this category are here referred

263 to as being "internal" ${ }^{39} \mathrm{Ar}$ atoms. For ${ }^{39} \mathrm{Ar}$ atoms bounded by one TOT layer whose other side is

264 a crystal surface, it is assumed that a point defect through the TOT layer exists adjacent to the

265 starting location of the ${ }^{39} \mathrm{Ar}$ atom. Such a defect is the result of crystal damage during ${ }^{39} \mathrm{Ar}$ recoil

266 (Hall et al., 1997, 2000). For such ${ }^{39} \mathrm{Ar}$ atoms, there is a 50\% chance that the atom can escape

267 through a bounding TOT layer if the atom is at its original coordinates in the hexagonal grid.

268 This scenario does an excellent job of simulating the enhanced loss of ${ }^{39} \mathrm{Ar}$ at low temperatures,

269 which in turn can explain why apparent ${ }^{40} \mathrm{Ar} * \rho^{39} \mathrm{Ar}$ ages for illite invariably start at or near a

270 value of zero (Dong et al., 1995; Hall et al., 1997, 2000).

271 As shown in Hall et al. (2000), the loss of Ar as a function the number of time steps

272 almost perfectly matches what would be expected for diffusion in an infinite cylinder (Crank, 
273 1979). In the case of diffusion in a continuum, the fraction $f$ of gas lost is a function of $\boldsymbol{x}=$

$274 \int \boldsymbol{D} / \boldsymbol{a}^{2} \boldsymbol{d t}$, where $D$ is the temperature dependent diffusion coefficient for $\mathrm{Ar}$ and $a$ is the radius

275 of the diffusing mica layer. There is an excellent linear fit between the simulation time step

276 number and $x$, using a uniform initial Ar concentration for ${ }^{40} \mathrm{Ar}^{*}$ and ${ }^{39} \mathrm{Ar}$ atoms in a circular disk

277 (i.e. infinite cylinder geometry), which indicates that a simple random walk model is an accurate

278 proxy for diffusion of Ar along illite interlayers.

279 An additional feature was introduced in Hall et al. $(1997,2000)$ to model the stereotypical

280 "hump-shaped" pattern frequently seen in illite age spectra. Specifically, those interlayers bound

281 on one side by only one TOT sheet were assumed to be less rigid, leading to enhanced diffusion

282 of both ${ }^{40} \mathrm{Ar}$ and ${ }^{39} \mathrm{Ar}$. It was arbitrarily assumed that diffusion coefficients along such interlayers

283 are 50\% higher than for internal, more rigid interlayers.

284 For a given $n_{a}$, the model assumes that the sample is made up of crystallites with thicknesses

$285 n_{a 1}$ and $n_{a 2}$, which are integers such that $\mathbf{n}_{\mathbf{a} 1} \leq \mathbf{n}_{\mathbf{a}} \leq \mathbf{n}_{\mathbf{a} 2}$. The fraction of crystallites with

286 thicknesses of $n_{a 1}$ and $n_{a 2}$ are $f_{1}$ and $f_{2}$ respectively where $f_{2}=\left(1 / f_{\text {recoil }}\right)-n_{a l}$ and $f_{1}=1-f_{2}$. In

287 order to model specific age spectra, the value of time steps for each gas fraction for the

288 distribution of crystallite's release of ${ }^{39} \mathrm{Ar}$ is determined that matches the actual release pattern 289 for ${ }^{39} \mathrm{Ar}$.

2914 RESULTS

292 Table 1 summarizes the results from the analysis of the samples. On the left-most

293 columns the results from XRD analyses are presented. Illite polytype characterization based on

294 XRD measurements of randomly oriented powders finds only two illite polytypes in the samples, $2952 \mathrm{M}_{1}$ and $1 \mathrm{M}_{\mathrm{d}}$, and quantifies the $\% 2 \mathrm{M}_{1}$ and $1 \mathrm{M}_{\mathrm{d}}$ polytypes (Haines and van der Pluijm, 2008 and 
Fitz-Díaz et al., 2014). $\% 2 \mathrm{M}_{1}$ varies between 10 and $100 \%$ in Sample 1, between 0 and $100 \%$ in

297 Sample 2 and between 0 and 65\% in Sample 3 (second column of Table 1 and Appendix 2).

298 Comparison of XRD patterns of air-dried and glycolated oriented preparations allows estimates

299 of the percentage of interlayered smectite (Moore and Reynolds, 1997), with less than 5\% of

300 smectite in some of the finer fractions and no detectable smectite in coarser fractions (third

301 column of Table 1 and Appendix 1). Measurements of air-dried, oriented preparations provides

302 illite crystallinity (IC) values, which were calibrated using Warr and Rice's (1994) approach

303 (IC*), with $\Delta 2 \theta$ ranges of $0.97-0.29,0.75-0.29$ and $0.69-0.34$, among the different grain size-

304 fractions of samples 1, 2 and 3, respectively. Smaller IC* corresponds to coarser size fractions,

305 while bigger IC* corresponds to finer size fractions (fourth column of Table 1). There is good

306 correlation between IC*, $\% 2 \mathrm{M}_{1}$ illite and $\%$ interlayered smectite, where more crystalline has the

307 highest proportion of $2 \mathrm{M}_{1}$ illite and the least presence of smectite.

308 Considering IC*, Bragg's angle for the 001 reflection of illite, the X-Ray wavelength

$309(\lambda=0.154 \mathrm{~nm}$ for a $\mathrm{Cu}$ XRD tube) and the shape factor in Scherrer Equation ( 1 , Fig. 5a), illite

310 crystallite thicknesses are calculated for all size-fractions, providing ICT ranges of 8.2-27.3,

$311 \quad 10.3-27.3$ and $11.5-23.6 \mathrm{~nm}$, for S1, S2 and S3. By dividing $I C T$ values by $1.0 \mathrm{~nm}$, the average

312 number TOT fundamental particles of illite are obtained (Fig. 1). Such ICT number corresponds

313 to the amount of potassium-bearing interlayers (Table 1), with smaller values for finer size-

314 fractions and bigger values for coarser fractions. The value of $I C T$ was used along with the

315 number of Ar-retentive interlayers $\left(n_{a}=1 / f_{\text {recoil }}\right)$ and total gas ages (TGAs) to determine X-Ray

316 Corrected Ages (XCA; Fig. 2). In all cases, TGAs are younger than RA in finer size-fractions,

317 and total gas ages are also significantly younger in the finest grain size-fraction of the samples.

318 Except for Sample 3, RAs are slightly younger in the coarser fractions than in finer fractions 
319 (Fig. 7). XCAs in the finest fractions give closer sample averages than TGAs and RAs. Values of 320 TGAs, RAs and XCAs are compiled Table 1 and Fig. 7.

\section{DISCUSSION} alteration units that contain negligible amounts of detrital illite (tiny muscovite flakes) and are mostly volcanic material and glass (Grim and Guven, 1978). The bentonitic shale layers $(<10$

$327 \mathrm{~cm})$ are interstratified in much thicker layers $(\geq 140 \mathrm{~cm})$ of Aptian limestone, which were

328 deposited after the worldwide sea rise that affected most of the Mexican region (Goldhammer,

329 1999) and was contemporaneous with extensive volcanism in western Mexico. Illite in the 330 samples was formed from volcanic material, together with calcite, quartz and traces of kaolinite 331 and chlorite, as are commonly found in anchizonal bentonitic layers (Hower et al., 1976; Sucha 332 et al., 1993). We find that illite grains are $90 \%$ of the sample and most of them with similar

333 shape and size, aligned with a strong cleavage subparallel to bedding (Fig. 4c-e). Such a cleavage 334 is related to bedding-parallel shear during flexural folding (Fitz-Díaz et al., 2012 and 2013; Fitz-

335 Díaz and van der Pluijm 2013; Wang et al., 2016) which in the study area occurred during one 336 major folding event (Padilla y Sánchez, 1982; Camerlo, 1998; Chávez-Cabello et al., 2004;

337 Higuera-Díaz et al., 2005).

338 Illite orientation with a strong shear-related cleavage is dominantly the result dissolution 339 of diagenetic grains and precipitation, and less a result of grain rotation, since no evidence of 340 kinking or bending of larger grains was observed in SEM (Ho et al., 1995). In fact, dissolution341 precipitation is the dominant illite reorientation mechanism in anchizonal-epizonal conditions 
342 (van der Pluijm et al., 1998). These conditions occurred in this area during folding, based on

343 temperatures of homogenization (above $200^{\circ} \mathrm{C}$ ) of fluid inclusions trapped in calcite and quartz

344 of fold-related veins (Gray et al., 2001; Fischer et al., 2009). This temperature range is also

345 consistent with the dominant illite grain size, with $>90 \%$ of illite has grains $>1 \mu \mathrm{m}$ and IC $*<0.4$,

346 which represents anchizonal-epizonal conditions (Merriman, 2005).

\subsection{Ar-degassing spectra, argon diffusion and Ar-age plateaus}

Since the landmark paper by Merrihue and Turner (1966), ${ }^{40} \mathrm{Ar} * \rho^{39} \mathrm{Ar}$ step-heating

350 experiments have been used to provide information on the spatial distribution of radiogenic

351 argon in the samples, as the release of argon is controlled by intracrystalline diffusion.

352 Hassanipak and Wampler (1996) investigated the effect of diameter and potassium content in

353 illite and glauconite on Ar release during stepwise heating and concluded that particle diameter

354 was less relevant than K content. However, Dong et al. $(1995,2000)$ noticed that in shale

355 samples from the Gulf Coast basin containing different illite polytypes/generations, particle size

356 indirectly affects illite composition, with concentration of younger (authigenic) $1 \mathrm{M}_{d}$ illite in finer

357 particles and older (detrital) $2 \mathrm{M}_{1}$ polytypes in coarser fractions. According to these authors, $1 \mathrm{M}_{\mathrm{d}}$

358 illite produces staircase shape spectra during the first steps of degassing because of its poorly

359 organized structure and because it has a lower $\mathrm{K}$ content (and hence ${ }^{40} \mathrm{Ar}^{*}$ ), while $2 \mathrm{M}_{1}$ illite

360 degassing at higher temperatures is constituted by discrete (detrital) illite with higher $\mathrm{K}$ content

361 in coarser fractions, producing flatter degassing patterns ("plateaus") such as those common in

362 metamorphic muscovite (Hall, 2014). However, such "plateaus" can be much higher than the

363 upper step of the initial staircase pattern when detrital illite is much older than authigenic illite.

364 Similar observations and interpretations where described by Kirschner et al. (1996) in Ar-Ar 
365 analyses of larger grains of white mica (2-6 $\mu \mathrm{m}$ in diameter), which is essentially coarse $2 \mathrm{M}_{1}$

366 illite, grown during multiple phases of mylonitic deformation developed in the Helvetic nappes.

367 To a first approximation, our Monte Carlo simulations explore the effects of grain

368 thickness, examining the effect of the $f_{\text {recoil }}$ derived Ar-retentive illite crystallite thickness $\left(n_{a}\right)$ on

369 the shape of Ar-degassing spectra patterns. Based on results from our samples, in which Ar-

370 degassing patterns significantly vary with grain size, we use XCA averages per site $(54.6,46.5$

371 and 51.1 for sample 1, 2 and 3, respectively) and global averages (50.7 My), and assume

372 homogeneous K and Ar concentration illite particles for model spectra. Similar shapes as in

373 experimental patterns of Figure 7, result for constant XCA and a range of $n_{a}$ or $f_{\text {recoil. }}$. As $f_{\text {recoil }}$

374 increases, there are greater distortions to the age spectra that are caused by recoil artifacts in

375 combination with the distribution of $n_{a 1}$ and $n_{a 2}$ values. In this suite of models, all of the

376 crystallites are assumed to have a single diameter. In the more realistic case where there is a

377 range of grain sizes (typically over a factor of 5), even greater distortions of the age spectral

378 shapes would be expected.

379 Age spectra shape variations can be evaluated by comparison of: (1) $f_{\text {recoil }}$, (2) steepness

380 of staircase degassing pattern at low temperature (first half of the spectrum), and (3) hump-

381 shaped (as opposite to flat-shaped) spectra at higher degassing temperatures (second half of the

382 spectrum). In illite samples, ${ }^{40} \mathrm{Ar} *{ }^{39} \mathrm{Ar}$ ratio variations can be affected by illite crystallite

383 thickness in different ways. For instance, in smaller illite crystallites the surface area to volume

384 ratio is greater, increasing the proportion of non-retentive sites Ar relative to retentive sites (Fig.

385 1b), which reduces the chance for recoiled ${ }^{39} \mathrm{Ar}$ to be retained within the crystallites during

386 neutron bombarding, thereby increasing $f_{\text {recoil }}$. A large surface area also increases spontaneous

387 loss by diffusion of weakly bounded radiogenic ${ }^{40} \mathrm{Ar} *$ on the edges of illite crystals (Huneke, 
1976) occasionally due to recoil during ${ }^{40} \mathrm{~K}-{ }^{40} \mathrm{Ar} *$ decay (Zimmermann and Odin, 1982). This

389 phenomenon has also been observed in large crystallites of standard quality silicates (Hall,

390 2014), and produces smaller ${ }^{40} \mathrm{Ar} *{ }^{39} \mathrm{Ar}$ ratios (i. e. ages) at lower temperature degassing steps. In

391 our model, Ar diffusion occurs from the surface (i.e., damaged external half layers and

392 spontaneously ${ }^{40} \mathrm{Ar} *$ depleted crystal edges) crystallite layers by Ar random walk along the

393 interlayers (Fig. 6), thus giving markedly younger ages in early heating steps and biasing to older

394 ages with temperature increase (Figs. 7 and 8). These abrupt age variations are purely due to

395 recoil artifacts that are revealed by temperature induced Ar-diffusion. Thicker illite crystallites

396 show smaller $f_{\text {recoil }}$, more rapid age increases, defining a steeper staircase in the first steps of

397 heating, and similar ages in the following steps due to grain homogeneity. This defines a flat or a

398 slight hump pattern shape that resembles an Ar age plateau (McDougall and Harrison, 1999).

399 Synthetic patterns of Fig. 8 resemble the same shape variations observed in experimental

400 patterns in the natural samples (Fig. 7). In all analyzed samples, illite degassing spectra show

401 similar spectra variations with grain size, with smaller $f_{\text {recoil }}$ and flatter shape spectra in coarser

402 fractions (particle diameter $>0.2 \mu \mathrm{m}$ and ICT $>15 \mathrm{~nm}$ ) and larger $f_{\text {recoil }}$ and prominent hump

403 shaped spectra in finer fractions (particle diameter $<0.2 \mu \mathrm{m}$ and ICT $<15 \mathrm{~nm}$ ). By comparison of

404 synthetic and experimental spectra variations and considering textural observations, we confirm

405 that the studied samples most likely contain one generation of illite with different grain size-

406 fractions, which might partly be induced during sample preparation. Thus, both illite polytypes

407 present in the samples $\left(2 \mathrm{M}_{1}\right.$ and $\left.1 \mathrm{M}_{\mathrm{d}}\right)$ are authigenic, since all ages are Paleogene-Eocene and

408 always significantly younger than deposition (Aptian-Albian). $2 \mathrm{M}_{1}$ illite, typically considered as

409 detrital, in this particular case is authigenic because deformation took place at relatively high

410 temperature conditions. 
Patterns with $f_{\text {recoil }}>0.2$ do not define meaningful plateau ages in synthetic or

412 experimental Ar-degassing spectra (figs. 7 and 8), even after applying the recoil-weighted age

413 correction to the degassing pattern, as proposed by Clauer et al. (2012). By comparing model and

414 experimental Ar-spectra and using $f_{\text {recoil }}$ as a common denominator, we find that illite age

415 interpretations based on plateaus significantly overestimate the true age of samples containing

416 one generation of illite with particle diameters smaller than $1 \mu \mathrm{m}(1000 \mathrm{~nm})$. Thus, illite age

417 determinations from Ar-spectra plateaus may be in error for samples containing fine-grain illite,

418 especially if samples contain different generations of illite.

\subsection{Illite age analysis and timing of folding.}

We use standard illite dating procedures (Haines and van der Pluijm, 2008) that plot ages

422 (TGA, RA and XCA) vs. \%2M 1 illite, with errors for the upper and lower intercepts from York

423 regression (Mahon, 1996). Results are shown in Figure 9 a-c, for samples 1, 2 and 3,

424 respectively. We find positive slopes in TGA vs. \%2M plots, with larger errors (shaded in

425 yellow) compared to RA and XCA plots. RA vs. \% $2 \mathrm{M}_{1}$ regression shows a negative slope for

426 samples 1 and 2, and a slightly positive slope for Sample 3. In general these plots have small age

427 errors. XCA vs. $\% 2 \mathrm{M}_{1}$ plots show flatter regression lines, with a very small negative slope in

428 samples 1 and 2 and a slightly positive slope in Sample 3. XCA's regression gives more closely

429 clustered ages and a better linear correlation with $\% 2 \mathrm{M}_{1}$ compared to TGA's and RA's. Even the

430 finest grain size-fractions $(<0.05 \mu \mathrm{m})$, which show more dispersion in TGA and RA plots, align

431 with ages of coarser grain size-fractions. Consequently, if samples contain one generation of

432 illite, ${ }^{40} \mathrm{Ar} /{ }^{39} \mathrm{Ar}$ age determination depends mostly on illite crystallite ordering and size. The X-

433 Ray corrected age (XCA) better defines illite ages and is in general more accurate and precise 
434 than RA and TGA for illite grain size-fractions with equivalent sphere diameters greater than 50

$435 \mathrm{~nm}$ and crystallite thickness between 10 and $50 \mathrm{~nm}$.

436 Fig $9 \mathrm{~d}$ plots ages for all three samples vs. ICT, in which, similar to plots of age vs. $\% 2 \mathrm{M}_{1}$

437 illite, XCA's show an almost horizontal regression line, negative slope for RA's and positive

438 slope for TGA's, with higher age dispersion in finer grains and age convergence of all samples in

439 coarser grains. These patterns show that ICT is more important than illite polytypes (which gives

440 a measure of 3D ordering and $\mathrm{K}$ content, although both vary linearly) and particle diameter for

441 the determination of true ages.

442 While ages of the three samples are very close to each other, we can test the conclusion that

443 all illite is contemporaneous or differing within a few Myr by modeling. We produced synthetic

444 patters for each grain size fraction, considering grain size and two ages: site average and global

445 average, representing by red and black synthetic degassing patterns, respectively (Fig. 8). In

446 samples 1 and 2, the site age average clearly differs from the global age average, while in

447 Sample 3 they are about the same within analytical error. With one exception (sample 1FM), age

448 site average (red synthetic pattern) better matches the experimental degassing patterns, which

449 implies that illite samples may have precipitated during slightly different times in the same

450 folding event that occurred during a time span between 55 and $47 \mathrm{Ma}$, corresponding to the XCA

451 averages of the oldest and youngest sample. We note that this time range is in excellent

452 agreement with deformation timing constrained by stratigraphy in the area (Lawton et al., 2009

453 and Gray and Lawton, 2011).

454

$455 \quad$ CONCLUSIONS 
Three bentonitic samples in a succession of platformal carbonates were affected by strong

457 bedding-parallel shear during the formation of km-scale folds. We analyzed four clay grain-size

458 fractions from illite-dominated samples that were collected along essentially the same folded

459 stratigraphic horizon (Fig. 3). XRD analysis shows that finer grain size-fractions $(<0.2 \mu \mathrm{m})$

460 dominantly contain weakly-ordered illite (1Md polytype), while coarser fractions contain mostly

461 muscovite-like $\left(2 \mathrm{M}_{1}\right)$ illite. Illite crystallite thickness increases (ICT) with degree of

462 crystallographic order of illite and particle diameter. All Ar-Ar illite ages are younger than the

463 depositional age, reflecting that illite in the samples is authigenic and, supported by stratigraphic

464 constraints, formed from alteration during a single folding event. Indeed, SEM observations of

465 rock fabric and systematic variations in experimental and synthetic ${ }^{40} \mathrm{Ar}-{ }^{39} \mathrm{Ar}$ degassing patterns

466 with ICT indicate that samples were formed about the same time under anchizonal conditions

467 (Table 1). This implies that Total Gas Ages underestimate the illite age, while Retention Ages

468 (Dong et al., 1995) overcorrect. Our XRD-based age correction method considers crystallite

469 thickness and the recoil fraction over a critical range of grain sizes that reflect the physical

470 properties of these illites, which provides ages between TGA and RA, with increased precision

471 and accuracy (error is smaller), especially when the finest grain-size fraction is excluded. On this

472 basis, we recommend analyzing illite grain size-fractions no less than $50 \mathrm{~nm}$ for most accurate

473 results and using XCA in the illite crystallite thickness (ICT) range of 10-50 nm.

474 A set of synthetic spectra of TGA and RA for grain populations with different $f_{\text {recoil }}$ but the

475 exact same age show significant differences in degassing patterns as the grain size changes from

476 thick to thin crystallites. Staircase pattern at low temperature degassing steps was related to

477 natural Ar loss during K-Ar decay on the edges of illite crystals (Huneke, 1976). In such a tiny

478 particles it is unlikely to have hydrothermally induced Ar-loss only affecting crystallites edges 
479 and not the cores of nanoparticles (i.e. Turner et al., 1966). Thus, age determination from Ar-age 480 plateaus would overestimate true age in these samples, as we see in multiple prior studies of illite 481 dating.

\section{ACKNOWLEDGEMENTS}

484 Research was supported by a U-M Turner Postdoctoral Fellowship to EFD and National Science 485 Foundation [grant number 1216750] to BvdP, as well as Conacyt [grants 240662 and 164454] to 486 EFD and Fernando Ortega-Gutiérrez. We thank Margarita Reyes and Sonia Angeles for help 487 with SEM analysis of the samples. We also most appreciate the careful reviews by Laura Webb 488 and anonymous of this manuscript, which greatly helped to improve the clarity and presentation.

490 REFERENCES

491 Aronson J. L. and Douthitt C. B. (1986) K/Ar systematics of an acid-treated illite/smectite: 492 implications for evaluating age and crystal structure. Clays and Clay Min 34, 473-482.

493 Beckinsale, R. D. and Gale, N. H. (1969) A reappraisal of the decay constants and branching 494 ratio of ${ }^{40}$ K. Earth Plan Sci Let 6(4), p. 289-294.

495 Camerlo, R. H. (1998) Geometric and kinematic evolution of detachment folds, Monterrey 496 salient, Sierra Madre Oriental, Mexico. M. S. thesis, University of Texas at Austin, 399 p.

497 Chávez-Cabello, G., Cossío-Torres, T. and Peterson-Rodríguez, R. H. (2004) Change of the 498 maximum principal stress during the Laramide Orogeny in the Monterrey salient, northeast 499 México. Geol Soc Am Special Paper 383, pp. 145-159. 
500 Clauer, N., Cocker, J. D. and Chaudhuri, S. (1992) Isotopic dating of diagenetic illites in 501 reservoir sandstones: Influence of the investigator effect. Origin, diagenesis, and petrophysics 502 of clay minerals in sandstones. Soc Econ Paleo Min Special Publication 47, pp. 5-12.

503 Clauer, N., Jourdan, F. and Zwingmann, H. (2011) Dating petroleum emplacement by illite $504{ }^{40} \mathrm{Ar}{ }^{39} \mathrm{Ar}$ laser stepwise heating: a comment. Am As Pet Geol Bull 95, pp. 2107-2111.

505 Clauer, N., Zwingmann, H., Liewig, N., and Wendling, R. (2012) Comparative ${ }^{40} \mathrm{Ar} /{ }^{39} \mathrm{Ar}$ and K506 Ar dating of illite-type clay minerals: A tentative explanation for age identities and 507 differences. Earth Sci Rev 115(1), pp. 76-96.

508 Clauer, N; Srodon, J., Francu, J. and Sucha, V. (1997) K-Ar dating of illite fundamental particles 509 separated from illite-smectite. Clay Min 32, pp. 181-196.

510 Coplen, T. B. (1988) Normalization of oxygen and hydrogen isotope data. Chem Geol 72, pp. $511 \quad 293-297$

512 Crank, J. (1979). The Mathematics of Diffusion: 2d Ed. Clarendon Press, Oxford UK.

513 Dixon, J. M. (2004) Physical (centrifuge) modeling of fold-thrust shortening across carbonate 514 bank margins-timing, vergence, and style of deformation, in K. R. McClay ed., Thrust 515 tectonics and hydrocarbon systems. AAPG Mem 82, pp. 223-238.

516 Dong, H., Hall, C. M., Halliday, A. N., Peacor, D. R., Merriman, R. J. and Roberts, B. (1997) $517{ }^{40} \mathrm{Ar} /{ }^{39} \mathrm{Ar}$ of Late Caledonian (Acadian) metamorphism and cooling of K-bentonites and slates 518 from the Welsh Basin, U. K. Earth Plan Sci Let 150, pp. 337-351.

519 Dong, H., Hall, C. M., Peacor, D. R. and Halliday, A. N. (1995) Mechanisms of argon retention 520 in clays revealed by laser ${ }^{40} \mathrm{Ar}-{ }^{39} \mathrm{Ar}$ dating. Science 267, pp. 355-359. 
521 Dong, H., Hall, C. M., Peacor, D. R., Halliday, A. N. and Pevear, D. R. (2000) Thermal ${ }^{40}$ Ar-

$522{ }^{39}$ Ar separation of diagenetic from detrital illitic clays in Gulf Coast shales. Earth Plan Sci Let $523 \quad$ 175, pp. 309-325.

524 Eberl, D. D., and Velde, B. (1989) Beyond the Kübler index. Clay Min 24(4), pp. 571-577.

525 Eguiluz-Antuñano, S., Aranda-García, M., and Marret, R. (2000) Tectónica de la Sierra Madre 526 Oriental, Mexico. Bol Soc Geol Mex 53, pp. 1-26.

527 Fischer, M. P., Higuera-Díaz, I. C., Evans, M. A., Perry, E. C. and Lefticariu, L. (2009).

528 Fracture-controlled paleohydrology in a map-scale detachment fold: Insights from the 529 analysis of fluid inclusions in calcite and quartz veins. J Struct Geol 31(12), pp.1490-1510.

530 Fitz-Díaz, E., and van der Pluijm, B. (2013) Fold dating: A new Ar/Ar illite dating application to 531 constrain the age of deformation in shallow crustal rocks. Jour Struc Geol 54, pp. 174-179.

532 Fitz-Díaz, E., Camprubí-Cano, A., Cienfuegos-Alvarado, E., Morales-Puente, P., Schleicher, A. 533 and van der Pluijm, B. (2014b) Illite as a fingerprint for fluid source during folding of shale 534 and limestone sequences, an example from the Mexican Fold-Thrust Belt. Earth Plan Sci Let 535 391, pp. 263-273.

536 Fitz-Díaz, E., Hudleston, P. and Tolson, G. (2011a) Comparison of tectonic styles in the 537 Mexican y Canadian Rocky Mountain Fold-Thrust Belt. In: Poblet, J. and Lisle, R. special 538 publication on Kinematics y Tectonic Styles of Fold-Thrust Belts. Geol Soc London 349, $539 \quad$ pp.149-167. 
540 Fitz-Díaz, E., Hudleston, P., Kirschner, D., Siebenaller, L., Camprubí, T., Tolson, G. and Pi541 Puig, T. (2011b) Insights into fluid flow and water-rock interaction during deformation of 542 carbonate sequences in the Mexican fold-thrust belt. Jour Struc Geol 33, p. 1237-1253.

543 Fitz-Díaz, E., Hudleston, P., Tolson, G., and van der Pluijm, B. (2014a) Progressive, episodic 544 deformation in the Mexican Fold-Thrust Belt (central Mexico): evidence from isotopic dating 545 of folds and faults. Intl Geol Rev 56, pp. 734-755.

546 Fitz-Díaz, E., Tolson, G., Hudleston, P., Bolanos-Rodriguez, D., Ortega-Flores, B., and 547 Vázquez-Serrano, A. (2012) The role of folding in the development of the Mexican fold-and$548 \quad$ thrust belt: Geosphere 8, pp. 931-949.

549 Foland, K. A., Hubacher, F. A. and Arehart, G. B. (1992) ${ }^{40} \mathrm{Ar}^{-39} \mathrm{Ar}$ dating of very fine-grained 550 samples-an encapsulated-vial procedure to overcome the problem of ${ }^{39} \mathrm{Ar}$ recoil loss. Chem $551 \quad$ Geol 102, pp. 269-276.

552 Goldhammer, R. K. (1999) Mesozoic sequence stratigraphy and paleogeographic evolution of 553 northeast Mexico in Bartolini, C., Wilson, J.L., Lawton, T.F. (eds.) Mesozoic sedimentary and 554 tectonic history of north-central Mexico. Geol Soc Am Special Paper 340, pp. 1-58.

555 Gray, G. G. and Lawton, T. F. (2011) New constraints on timing of Hidalgoan (Laramide) 556 deformation in the Parras and La Popa basins, NE Mexico. Bol Soc Geol Mex 63, pp. 333-343

557 Gray, G. G., Pottorf, R. J., Yurewicz, D. A., Mahon, K. I., Pevear, D. R., Chuchla, R. J. (2001). 558 Thermal and chronological record of syn-to post-Laramide burial and exhumation, Sierra 559 Madre Oriental, Mexico. AAPG Memoir 75, pp.159-181. 
560 Grim, R. E. (1968) Clay Mineralogy, $2^{\text {nd }}$. Ed. McGraw-Hill, New York, 596 p.

561 Grim, R. E., \& Guven, N. (1978) Bentonites: geology, mineralogy, properties and uses. Elsevier 56224.

563 Hacker, B. R., Yin, A., Christie, J. M., \& Davis, G. A. (1992). Stress magnitude, strain rate, and 564 rheology of extended middle continental crust inferred from quartz grain sizes in the Whipple 565 Mountains, California. Tectonics, 11(1), pp. 36-46.

566 Haines, S. and van der Pluijm, B. (2008) Clay quantification and Ar dating of synthetic and 567 natural gouge: Application to the Miocene Sierra Mazatlán detachment fault, Sonora, Mexico. $568 \quad$ Jour Struct Geol 30, pp. 525-538.

569 Hall, C. M. (2014) Direct measurement of recoil effects on ${ }^{40} \mathrm{Ar}^{39} \mathrm{Ar}$ standards. Geol Soc $570 \quad$ London Special Publications 378, pp. 53-62.

571 Hall, C. M., Higueras, P., Kesler, S. E., Lunar, R., Dong, H. and Halliday, A. N. (1997) Dating 572 of alteration episodes related to mercury mineralization in the Almade'n district, Spain. Earth $573 \quad$ Plan Sci Let 148, 287-298.

574 Hall, C. M., Kesler, S., Simon, G. and Fortuna, J. (2000) Overlapping Cretaceous and Eocene 575 Alteration, Twin Creeks Carlin-Type Deposit, Nevada. Econ Geol 95, pp. 1739-1752.

576 Halliday, A. N. (1978) ${ }^{40} \mathrm{Ar}-{ }^{39} \mathrm{Ar}$ stepheating studies of clay concentrates from Irish orebodies. 577 Geoch Cosmo Acta 42, pp. 1851-1858. 
578 Hassanipak A. A. and Wampler J. M. (1996) Radiogenic Argon Released by Stepwise Heating of 579 Glauconite and Illite: The Influence of Composition and Particle Size. Clays Clay Min 44, pp. $580 \quad 717-726$.

581 Hess, J. C. and Lippolt, H. J. (1986) Kinetics of Ar isotopes during neutron irradiation; ${ }^{39} \mathrm{Ar}$ loss 582 from minerals as a source of error in ${ }^{40} \mathrm{Ar} /{ }^{39} \mathrm{Ar}$ dating. Chem Geol 59, pp. 223-236.

583 Higuera-Diaz, I., Fischer, M. P. and Wilkerson, M. S. (2005). Geometry and kinematics of the 584 nuncios detachment fold complex; implications for lithotectonics in northeastern Mexico. 585 Tectonics 24(4), pp. 1-19.

586 Ho, N. C., Peacor, D. R. and van der Pluijm, B. A. (1995). Reorientation mechanisms of 587 phyllosilicates in the mudstone-to-slate transition at Lehigh Gap, Pennsylvania. J Struct Geol $588 \quad$ 17(3), pp. 345-356.

589 Hower, J., Eslinger, E., Hower, M. E. and Perry, E. A. (1976) Mechanism of burial 590 metamorphism of argillaceous sediment; 1, mineralogical and chemical evidence. Geol Soc $591 \quad$ Am Bull 87(5), pp.725-737.

592 Huneke, J. C. (1976) Diffusion artifacts in dating by stepwise thermal release of rare gases. $593 \quad$ Earth Plan Sci Let 28(3), pp. 407-417.

594 Kirschner, D. L., Cosca, M. A., Masson, H., \& Hunziker, J. C. (1996). Staircase 40/Ar39Ar 595 spectra of fine-grained white mica: Timing and duration of deformation and empirical 596 constraints on argon diffusion. Geology 24(8), pp.747-750. 
Kübler, B. (1967) La cristallinité de l'illite et les zones tout à fait supérieures du metamorphisme. Étages tectoniques. Colloque de Neuchâtel 18-21, pp. 105-122.

Kübler, B. (1968) Évaluation quantitative du métamorphisme para la cristallinité de l'illite; état 600 des progrès realisés ces dernières années. Centre de Recherches de Pau (Societé Nationale des Petôoles d'Aquitaine) 2, pp. 385-397.

Lawton, T. F., Bradford, I. A., Vega-Vera, F. J., Gehrels, G. E. and Amato, J. M. 2009.

603 Provenance of Upper Cretaceous-Paleogene sandstone in the foreland basin system of the

604 Sierra Madre Oriental, Northeastern Mexico, and its bearing on the fluvial dispersal systems 605 of the Mexican Laramide Province. Geol Soc Am Bull 121, pp. 820-836.

Mahon, K. (1996) The new "York" regression, application of an improved statistical method to 607 geochemistry. Int Geol Rev 38, pp. 293-303.

Marrett, R. and Aranda-García, M. (1999) Structure and kinematic development of the Sierra 609 Madre Oriental fold-thrust belt, Mexico. Wilson, JL, Ward, WC, Marrett, R., Stratigraphy and 610 structure of the Jurassic and Cretaceous platform and basin systems of the Sierra Madre 611 Oriental. Field book: San Antonio, Texas, South Texas Geological Society, pp. 69-98.

612 McDougall, I. and Harrison, T. M. (1999) Geochronology and Thermochronology by the 613 ${ }^{40} \mathrm{Ar}{ }^{39} \mathrm{Ar}$ method. Oxford University Press, New York $\mathbf{2}^{\text {nd }}$ ed, $212 \mathrm{p}$

614 Merrihue, C. and Turner, G. (1966) Potassium/argon dating by activation with fast neutrons. 615 Jour Geoph Res 71(11), pp. 2852-2857. Mahon, K., 1996. The new "York" regression; 616 application of an improved statistical method to geochemistry. International Geology Review $617 \quad 38,293-303$. 
618 Merriman R. J. and Peacor, D. R. (1999) Very-low grade metapelites: mineralogy, microfabrics 619 and measuring reaction progress, in Frey, M. and Robinson, D., eds., Low-Grade 620 Metamorphism. Blackwell Science, UK, pp. 10-60.

621 Merriman, R. J. (2005) Clay minerals and sedimentary basin history. Eur Jour Min 17(1), pp. 162220.

623 Moore, D. M. and Reynolds, R. C. Jr. (1997) X-ray diffraction and the identification and analysis 624 of clay minerals. Oxford University Press, United Kingdom. 373 p.

625 Onstott, T. C., Miller, M. L., Ewing, R. C., Arnold, G. W. and Walsh, D. S. (1995) Recoil 626 refinements: implications for the 40Ar-39Ar dating technique. Geoch Cosmo Acta 59(9), pp. $627 \quad 1821-1834$.

628 Osborn S. G., Duffield L. T., Elliott W. C., Wampler J. M., Elmore R. D. and Engel M. H. 629 (2014) The timing of diagenesis and thermal maturation of the Cretaceous Marias River 630 Shale, Disturbed Belt, Montana. Clays Clay Min 62(2), pp. 112-125.

631 Padilla y Sánchez, R. J. (1982) Geologic evolution of the Sierra Madre Oriental between Linares, 632 Concepción del Oro, Saltillo, and Monterrey, Mexico. PhD Thesis, University of Texas at $633 \quad$ Austin, 217 p.

634 Patterson, A. L. (1939). The Scherrer formula for X-ray particle size determination. Physical $635 \quad$ review, 56(10), 978.

636 Peacor, D. R. (1992) Diagenesis and low-grade metamorphism of shales and slates. Rev Min 637 Geoch 27(1), pp. 335-380. 
638 Pessagno, E. A., Jr. (1969) Upper Cretaceous stratigraphy of the western Gulf Coast area of 639 Mexico, Texas and Arkansas. Geol Soc Am Memoir 111, pp. 1-139.

640 Pevear, D. R. (1999) Illite and hydrocarbon exploration. Proceedings of the National Academy of $641 \quad$ Sciences 96, pp. 3440-346.

642 Scherrer, P. (1918). Bestimmung der Grösse und der inneren Struktur von Kolloidteilchen 643 mittels Röntgenstrahlen. Nachrichten von der Gesellschaft der Wissenschaften zu Göttingen, 644 mathematisch-physikalische Klasse, pp. 98-100.

645 Seidemann, D. E. (1976) K-Ar and ${ }^{40} \mathrm{Ar} /{ }^{39} \mathrm{Ar}$ dating of deep-sea rocks. PhD thesis, Yale 646 University.

647 Sletten V. W. and Onstott T. C. (1998) The thermal instability of muscovite during in vacuo 648 heating: Implications for Ar loss systematics in the laboratory. Geoch Cosmo Acta 62, pp.123649141.

650 Smith P. E., Evensen N. M. and York D. (1993) First successful ${ }^{40} \mathrm{Ar}-{ }^{39} \mathrm{Ar}$ dating of glauconies: 651 Argon recoil in single grains of cryptocrystalline material. Geology 21, pp. 41-44.

652 Solum, J. S. and Van der Pluijm, B. A. (2007) Reconstructing the Snake River-Hoback River 653 Canyon section of the Wyoming thrust belt through direct dating of clay-rich fault rocks. Geol 654 Soc Am Special Paper 433, pp. 183-196.

655 Sucha, V., Kraus, I., Gerthofferova, H., Petes, J. and Serekova, M. (1993). Smectite to illite 656 conversion in bentonites and shales of the East Slovak Basin. Clay Min 28, 243-243. 
657 Szczerba, M., Derkowski, A., Kalinichev, A. G. and Środoń, J. (2015) Molecular modeling of 658 the effects of ${ }^{40} \mathrm{Ar}$ recoil in illite particles on their K-Ar isotope dating, Geoch Cosmo Acta, in 659 press.

660 Turner, G. and Cadogan, P. H. (1974) Possible effects of ${ }^{39} \mathrm{Ar}$ recoil in ${ }^{40} \mathrm{Ar}-{ }^{39} \mathrm{Ar}$ dating. Lunar 661 and Planetary Science Conference Proceedings 5, pp. 1601-1615.

662 Turner, G., Miller, J. A. and Grasty, R. L. (1966) The thermal history of the Bruderheim 663 meteorite. Earth Plan Sci Let 1(4), pp. 155-157.

664 van der Pluijm, B. A. Ho, N., Peacor, D. R. and Merriman, R. J. (1998). Contradictions of slate 665 formation resolved? Nature (London) 392, pp. 348.

666 van der Pluijm, B. A., Hall, C. M, Vrolijk, P. J., Pevear. D. R. and Covey. M. C. (2001). The 667 dating of shallow faults in the Earth's crust. Nature 412, pp.172-175.

668 Verdel, C., van der Pluijm, B. and Niemi, N. (2011) Variations in the illite to muscovite 669 transition related to metamorphic conditions and detrital muscovite content; insight from the 670 Paleozoic passive margin of the southwestern United States. Jour Geol 119, pp. 419-437.

671 Wang, Y., Zwingmann, H., Zhou, L., Lo, C. H., Viola, G., and Hao, J. (2016). Direct dating of 672 folding events by ${ }^{40} \mathrm{Ar} /{ }^{39} \mathrm{Ar}$ analysis of synkinematic muscovite from flexural-slip planes. $673 \quad$ Jour Struct Geol 83, pp. 46-59.

674 Warr, L. N. and Rice, A. H. N., 1994. Interlaboratory standardization and calibration of clay 675 mineral crystallinity and crystallite-size data. Jour Met Geol 12, pp. 141-152. 
676 Ylagan, R., Kim, C., Pevear, D. and Vrolijk, P. 2002. Illite polytype quantification for accurate $677 \quad$ K-Ar determination. Am Min 87, pp. 1536-1545.

678 Zimmermann, J. L. and Odin, G. S. (1982) Kinetics of the release of argon and fluids from 679 glauconies. Numerical Dating in Stratigraphy, pp. 345-362.

680 


\section{FIGURE CAPTIONS}

Figure 1. Fundamentals on illite crystallography. (a) Crystalline structure of illite, a phyllosilicate constituted by two silica tetrahedral sheets (T) with an octahedral sheet unit $(\mathrm{O})$ in between. The three layers together (TOT), along with the cation (potassium) connecting them, constitutes the fundamental particle of illite, which has an average thickness of $1 \mathrm{~nm}$ (Grim, 1968). (b) Multiple TOT units constitute illite crystallites, which have an average thickness determined by the number of stacked fundamental units, also known as illite crystallite thickness (ICT). Illite stacks also commonly contain interlayered smectite and imperfections (i. e., dislocations and vacancies; Peacor, 1992), which cannot retain argon.

Figure 2. Total-Gas Age or TGA (a), Retention Age or RA (b) and the X-Ray Diffraction, recoil fraction based Age (XCA). For example, in a sample with an average $I C T=10 \mathrm{~nm}$ and a fraction of recoil $\left(\mathrm{f}_{\text {recoil }}\right)$ of $0.25, \mathrm{ICT}=10, \mathrm{na}=1 / 0.25=4$ and XCA=(40/33)TGA (see Table $1)$.

Figure 3. Geological setting of samples. (a) Landsat and Google Earth images northern Mexico and the Monterrey Salient, respectively, showing the location and geomorphological expression of regional folds in the study area. (b) Synthetic geological map of the study area showing the location of sampling sites (based on map Padilla y Sánchez, 1982). (c) Cross section showing the geometry of the studied buckle folds and the relative of sampling sites (based on cross section by Padilla y Sánchez, 1982). S1=Sample 1, S2=Sample 2 and S=Sample 3.

Figure 4. (a) Cupido Fm. outcrop on the back limb of Clavelillas Anticline. (b) Close up to sampling site where we see highly sheared reddish shale layers interbedded with thickly 
bedded limestone. Below, SEM secondary electron images showing textural aspects of the 707 studied samples: (c) surface of Sample 1 (S1) showing a homogeneous granular texture and 708 continuous cleavage with illite grains oriented parallel; (d) close-up of cleavage domains in 709 Sample 3 (S3), again, illite grains show homogeneous size and disposition across the 710 samples; (e) illite grains of Sample 3 with a view perpendicular to that in (d) also showing 711 homogeneous grain size of illite flakes. I=illite, $\mathrm{C}=$ calcite.

712 Figure 5. XRD sample characterization. (a) Schematic representation that shows how 713 calibrated illite crystallinity (IC, Warr and Rice, 1994) can be used in the Scherrer Equation 714 (Patterson, 1939) to determine average illite crystallite thickness with $\lambda=0.154 \mathrm{~nm}$ for a $\mathrm{Cu}$ 715 XRD tube and the shape factor $K^{\sim} 1$ (Moore and Reynolds, 1997). (b) Sketch showing the 716 structure of $2 \mathrm{M}_{1}$ and $1 \mathrm{M}_{\mathrm{d}}$ illite polytypes and their XRD patterns (modified from Haines and 717 van der Pluijm, 2008).

718 Figure 6. Schematic representation of premises for the argon diffusion model in illite based 719 on work by Hall et al. $(1997,2000)$. Note that Ar is assumed to randomly walk along the 720 interlayers and escapes from the most external layers during degassing.

721 Figure 7. ${ }^{40} \mathrm{Ar} /{ }^{39} \mathrm{Ar}$-degassing spectra obtained in the four different clay size-fractions from 722 samples that were collected in three folds. Total gas ages (TGA), retention ages (RA) and 723 fraction of recoil $\left(f_{\text {recoil }}\right)$ are indicated for each aliquot. Degassing patterns of fine-grained 724 samples are indicated in yellow, fine-medium in orange, medium-coarse in red and coarse in 725 deep-red.

726 Figure 8. Comparison of experimental (color-coded for the samples according to Table 1)

727 and synthetic degassing patterns considering $f_{\text {recoil }}$, as well as XCA's, site average age (54.9, $728 \quad 46.5$ and 51.1 Ma, for samples 1, 2 and 3, respectively) and global average age (50.8 My), 
729 red and black synthetic degassing patterns, respectively. Note that red (age average per site)

730 patterns provide a better fit to the experimental patterns. All of the synthetic age spectra use a

731 single grain size and the ICT distribution above. The model age spectra are scaled so that

732 they have either a site specific XCA or a globally averaged XCA. In spite of the simplicity of

733 the model used, the concordance between measured age spectra and model age spectra is

734 remarkable, especially for site averaged XCAs, which supports the hypothesis that site

735 averaged XCAs represent the time of illite formation during folding.

736 Figure 9. Illite Dating. (a), (b) and (c) show TGA, RA and XCA vs. 2M $\mathrm{M}_{1}$ plots for samples 1,

7372 and 3, respectively. York regression errors for upper and lower intersection are shown in

738 blue for TGA, in pink for RA and in grey for XCA (following procedure in Mahon, 1996).

739 (d) XCA vs. ICT showing that age dispersion is more important in smaller grain size-

740 fractions compared to samples with thicker crystallites. Symbols in pale-green correspond to

741 Sample 1, pale-blue to Sample 2 and pale-orange to Sample 3.

742 Table 1: Results from all analytical tools applied to the studied samples, including illite

743 crystallographic properties and Ar-Ar illite age (TGA, RA and XCA) determined in illite

$744 \quad$ concentrates. 
Table 1. Results from all analytical tools applied to the studied samples, including illite crystallographic properties and Ar-Ar illite age (TGA, RA and XCA) in illite concentrates.

\begin{tabular}{|c|c|c|c|c|c|c|c|c|c|}
\hline Sample & $\% 2 M_{1}$ & $\% \mathrm{Sm}$ & $\mathrm{IC}^{*}(\Delta 2 \theta)$ & ICT(nm) & TGA (Myr) & RA (Myr) & $f_{\text {recoil }}$ & $n_{a}$ & XCA (Myr) \\
\hline $1-F$ & $10 \pm 2$ & $<5 \%$ & 0.97 & 8.2 & $46.4 \pm 0.22$ & $63.6 \pm 0.31$ & 0.28 & 3.6 & $55.9 \pm 0.27$ \\
\hline 1-FM & $18 \pm 3$ & $<5 \%$ & 0.86 & 9.2 & $49.1 \pm 0.22$ & $62 . \pm 0.28$ & 0.22 & 4.6 & $55.9 \pm 0.25$ \\
\hline 1-MC & $35 \pm 5$ & $\sim 0 \%$ & 0.46 & 17.2 & $49.3 \pm 0.21$ & $57.5 \pm 0.24$ & 0.15 & 6.8 & $54.3 \pm 0.23$ \\
\hline $1-C$ & $100 \pm 5$ & $\sim 0 \%$ & 0.29 & 27.3 & $49.2 \pm 0.25$ & $54.5 \pm 0.27$ & 0.10 & 10.3 & $52.5 \pm 0.27$ \\
\hline $2-F$ & $0 \pm 2$ & $<5 \%$ & 0.75 & 10.7 & $36.1 \pm 0.23$ & $50.4 \pm 0.32$ & 0.29 & 3.4 & $45.7 \pm 0.29$ \\
\hline 2-FM & $30 \pm 4$ & $\sim 0 \%$ & 0.59 & 13.5 & $42.4 \pm 0.25$ & $51.9 \pm 0.30$ & 0.19 & 5.3 & $48.4 \pm 0.29$ \\
\hline 2-MC & $80 \pm 5$ & $\sim 0 \%$ & 0.37 & 21.4 & $43.5 \pm 0.21$ & $48.7 \pm 0.24$ & 0.11 & 9.2 & $46.5 \pm 0.22$ \\
\hline $2-C$ & $100 \pm 5$ & $\sim 0 \%$ & 0.29 & 27.3 & $43.6 \pm 0.28$ & $47.3 \pm 0.30$ & 0.08 & 13.2 & $45.5 \pm 0.29$ \\
\hline 3-F & 0 & $<5 \%$ & 0.69 & 11.5 & $39.7 \pm 0.23$ & $53.1 \pm 0.30$ & 0.26 & 3.9 & $48.9 \pm 0.28$ \\
\hline 3-FM & $16 \pm 2$ & $\sim 0 \%$ & 0.50 & 16.0 & $45.6 \pm 0.18$ & $54.6 \pm 0.22$ & 0.17 & 5.8 & $51.5 \pm 0.20$ \\
\hline 3-MC & $40 \pm 3$ & $\sim 0 \%$ & 0.38 & 20.8 & $49.3 \pm 0.18$ & $53.7 \pm 0.19$ & 0.09 & 11.8 & $51.4 \pm 0.19$ \\
\hline 3-C & $65 \pm 3$ & $\sim 0 \%$ & 0.34 & 23.6 & $51.8 \pm 0.17$ & $54.4 \pm 0.18$ & 0.05 & 19.6 & $52.6 \pm 0.17$ \\
\hline
\end{tabular}

$\% 2 \mathrm{M}_{1}$ =fraction of $2 \mathrm{M}_{1}$ illite polytype wrt $2 \mathrm{M}_{1}+1 \mathrm{M}_{\mathrm{d}}$ polytypes; \%Sm= smectiteproportion in illite-smectite; IC*=Illite crystallinity calibrated according to Warr and Rice (1994); ICT= average illite crystallite thickness; TGA=Total Gas Age; RA=Retention Age; $f_{\text {recoil }}=$ fraction of recoil; $n_{a}=$ average number of continuous Ar retentive TOT layers; XCA=XRD based corrected age. 


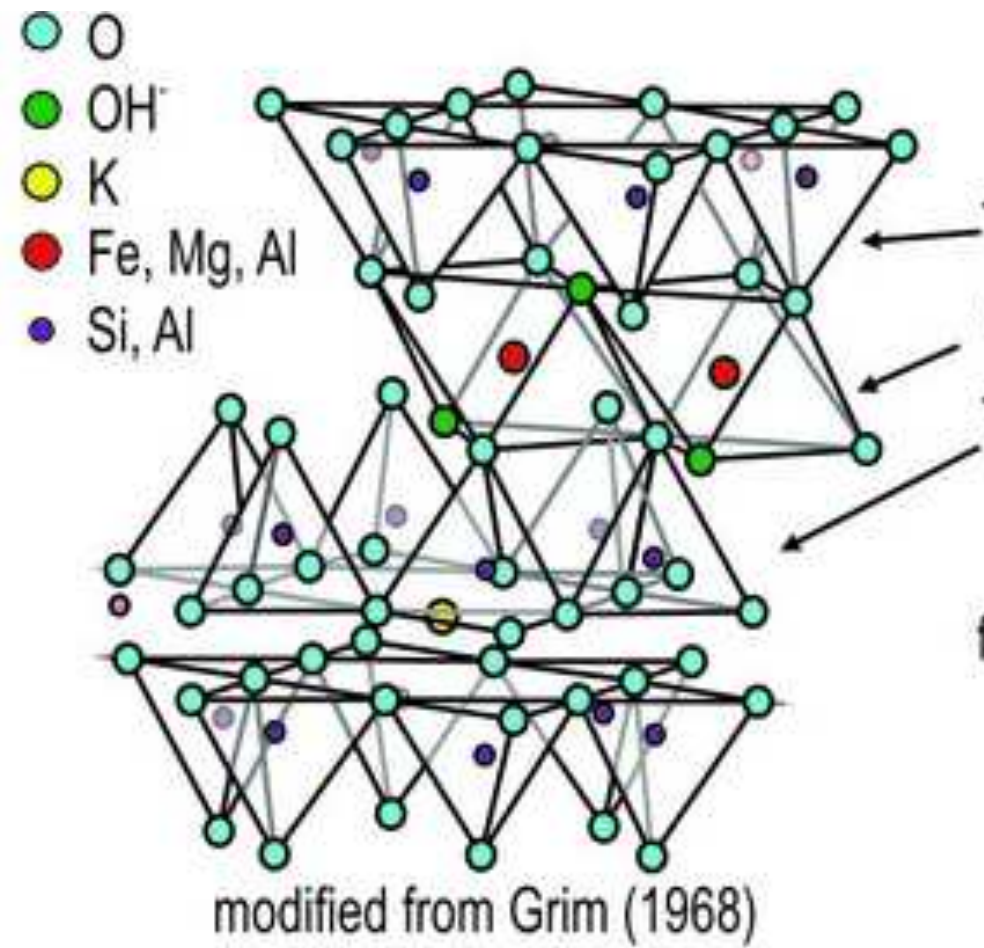

\section{(a) Crystalline structure} half bound layer

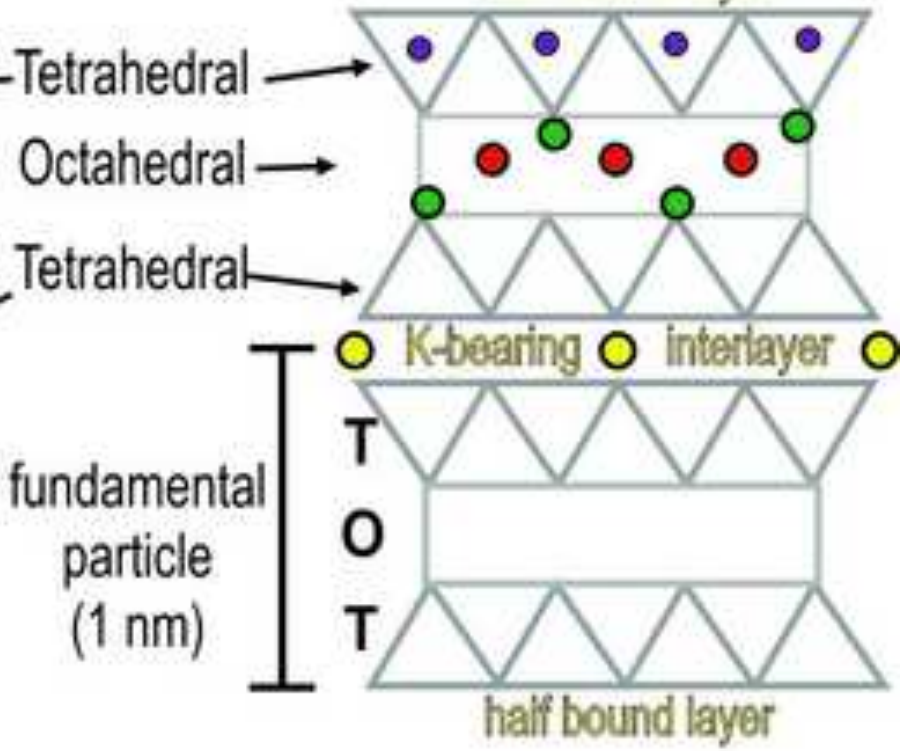

(b) Illite crystal viewed perpendicular to the c-axis

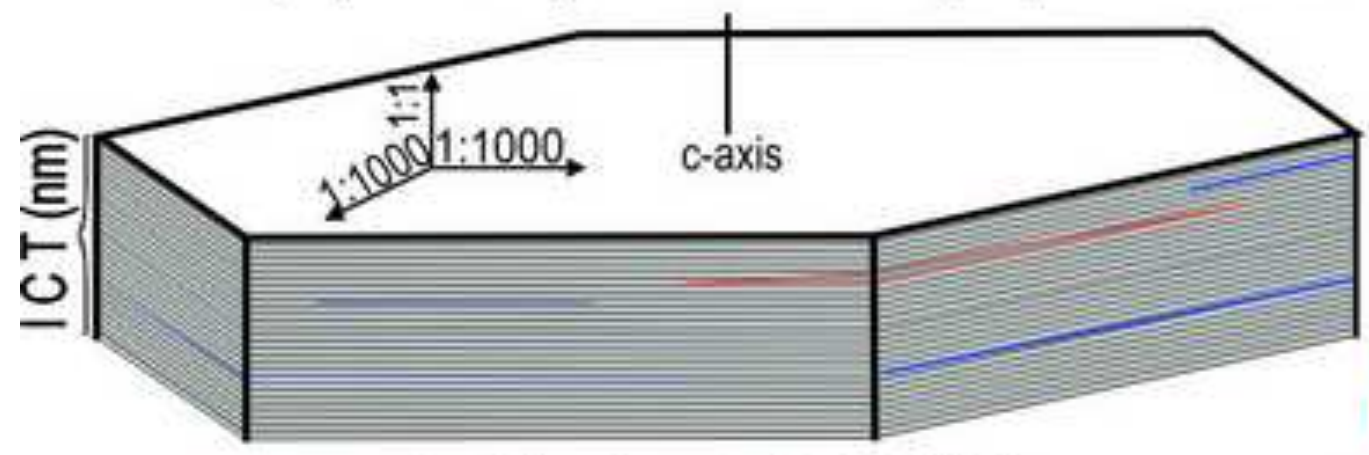

retentive sites

Illite fundamental part. non-retentive sites dislocations Smectite layers

Particle diameter $\left(\approx I C T \times 10^{3}\right)$ 
(a) Total-Gas Age Model

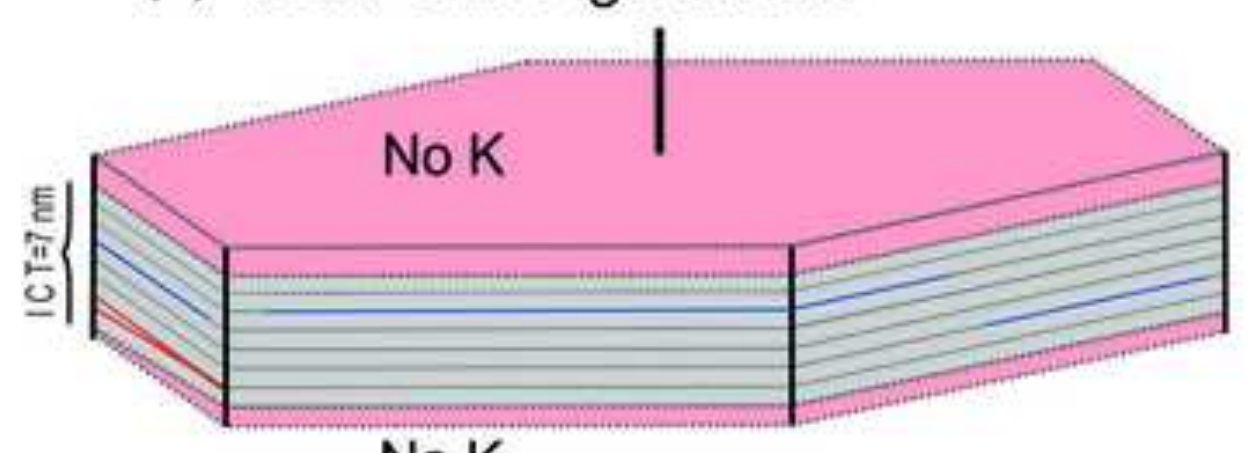

No K

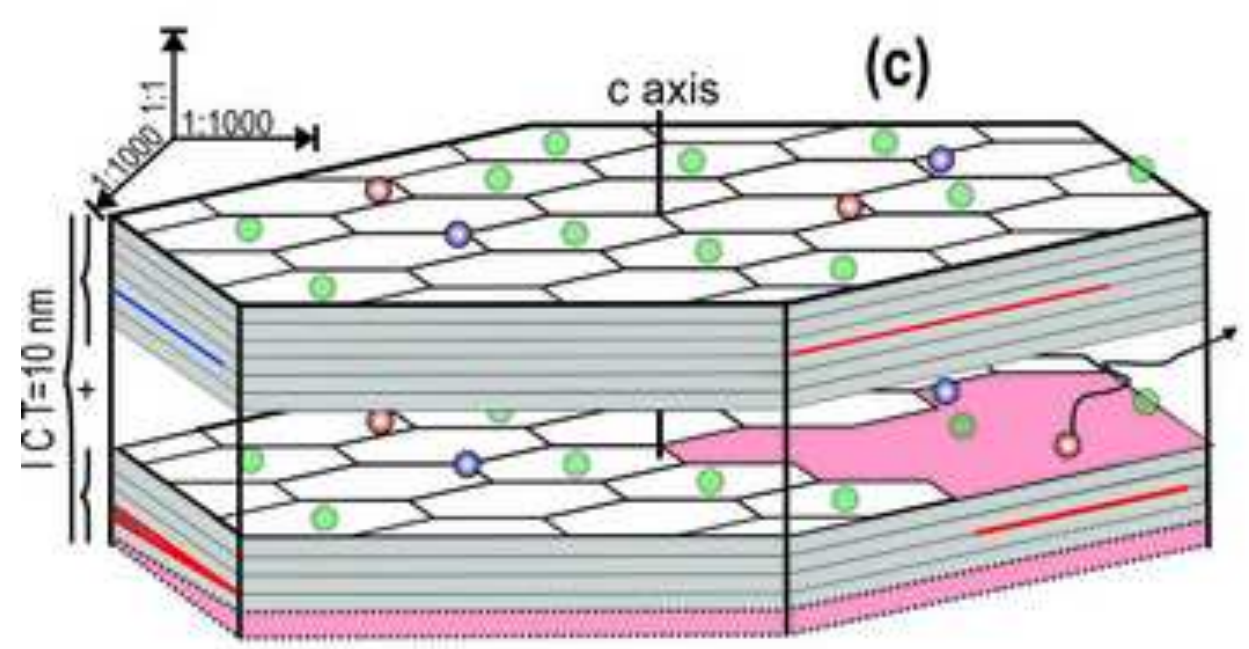

(b) Retention Ar-Ar Age Model

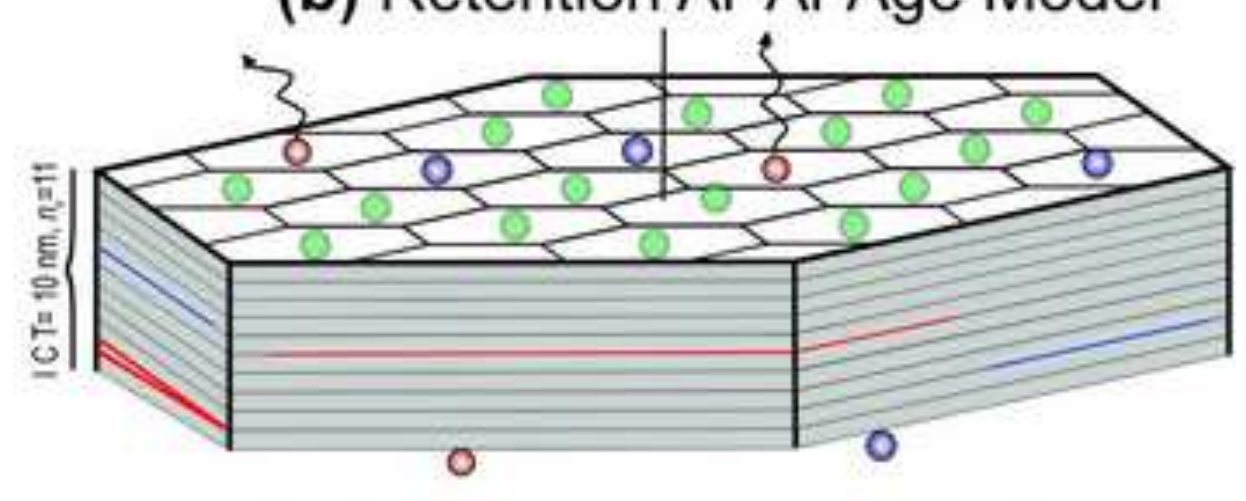

retentive sites

non-retentive sites

$\square$ llite fundamental particles

Cystal dislocation

Smectite layers

$\mathrm{O}^{*} \mathrm{Ar} \mathrm{O}^{*} \mathrm{Ar}^{*} \mathrm{~K} \mathrm{O}^{*} \mathrm{Ar}^{*}$ spontaneous escape on the half layers

(c) XRD Ar-Ar Age Correction Model

ICT $(\mathrm{nm})=\#$ TOT layers $=10$

$n_{a}=1 / f_{\text {mod }} n_{a} \sim 4$ (recoil -0.25 )

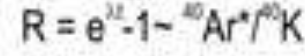

$\lambda$ is the total decay constant of " $K$

\section{Figure 2}



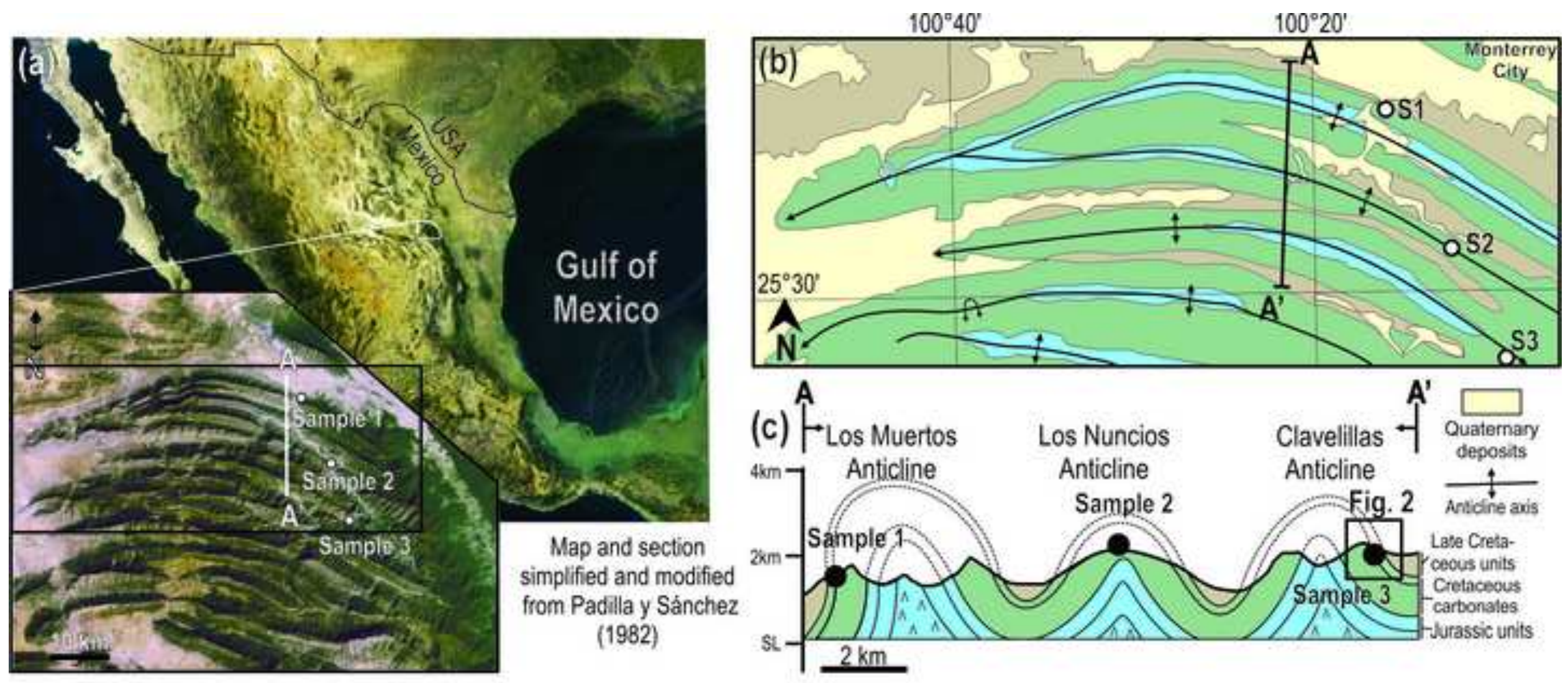

Figure 3 
(a)

Cretaceous carbonates (Cupido Fm.)
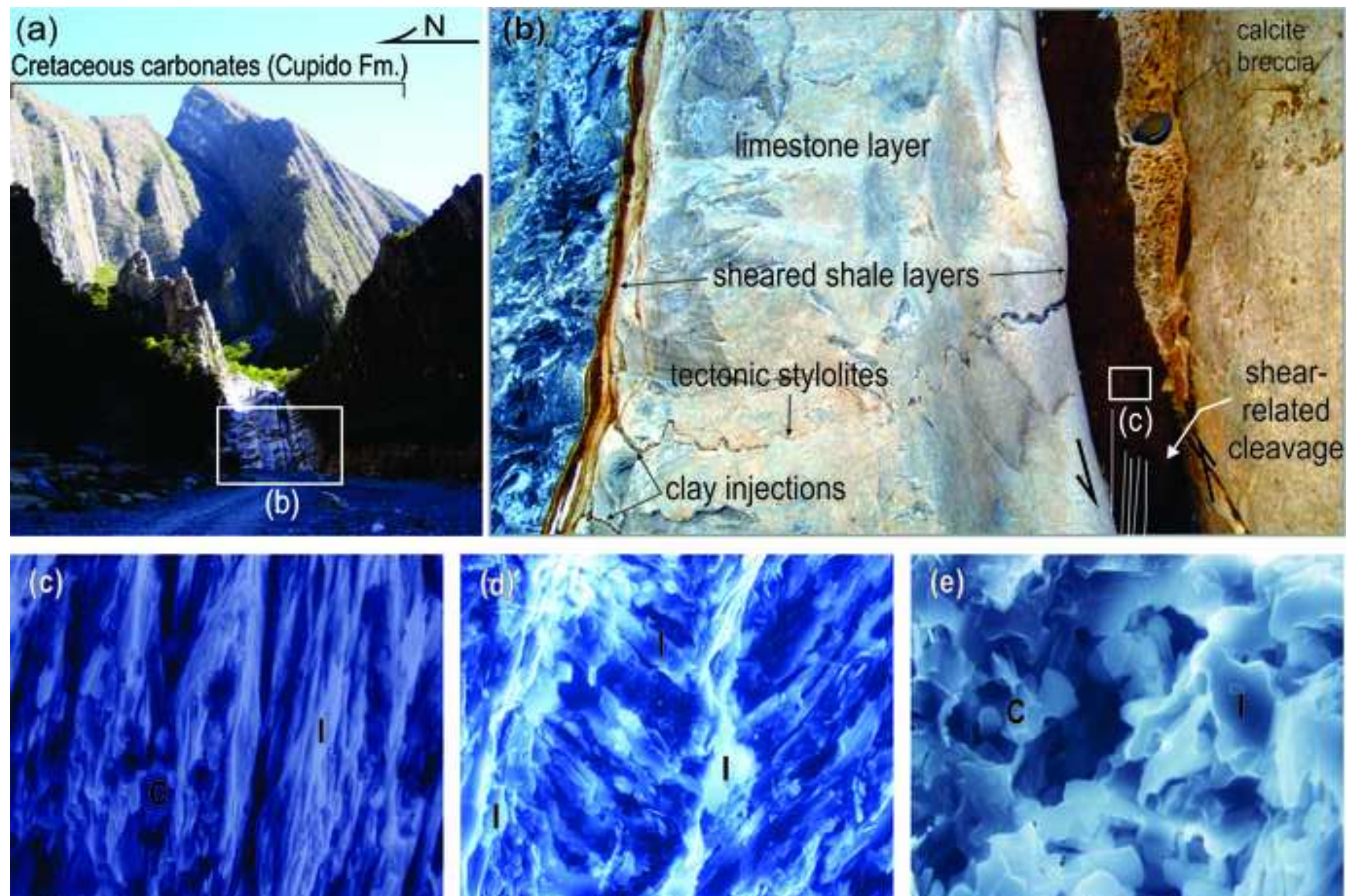

$10 \mu \mathrm{m}$
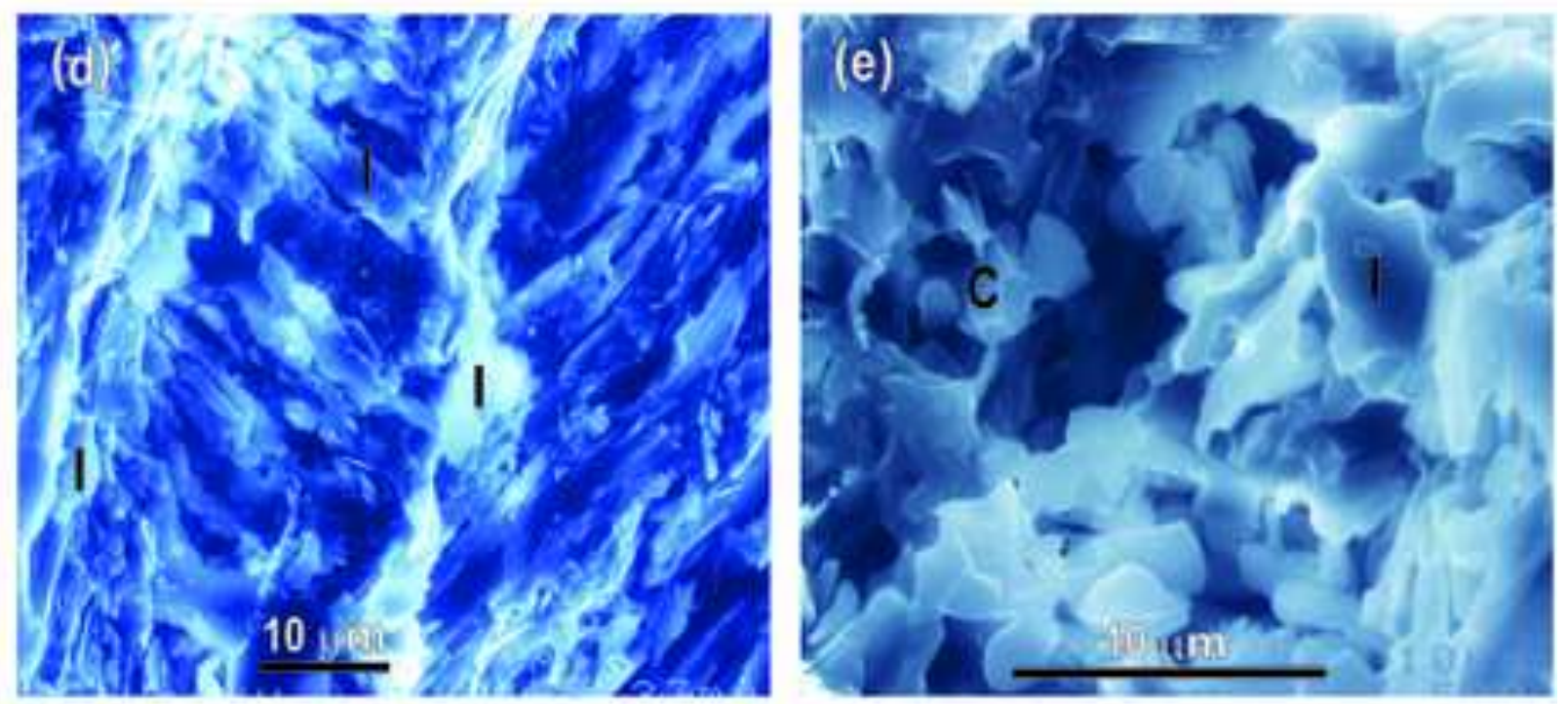

Figure 4 

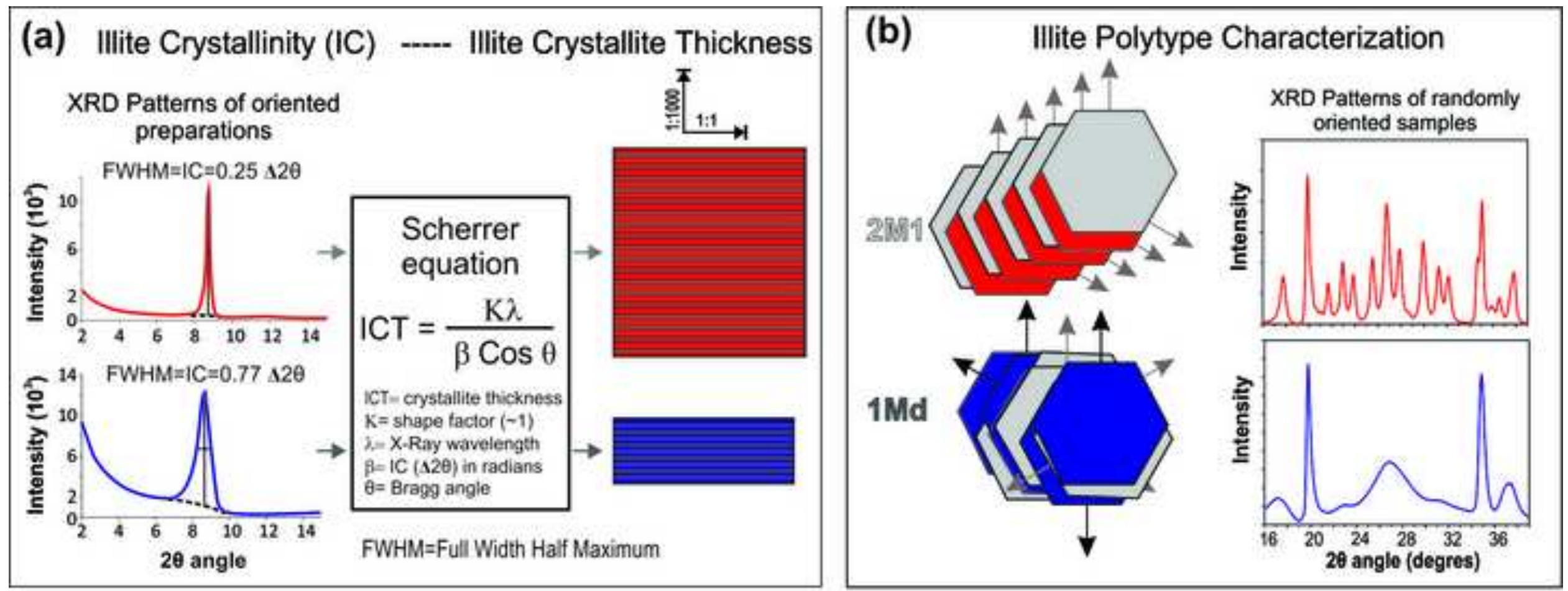

\section{Figure 5}




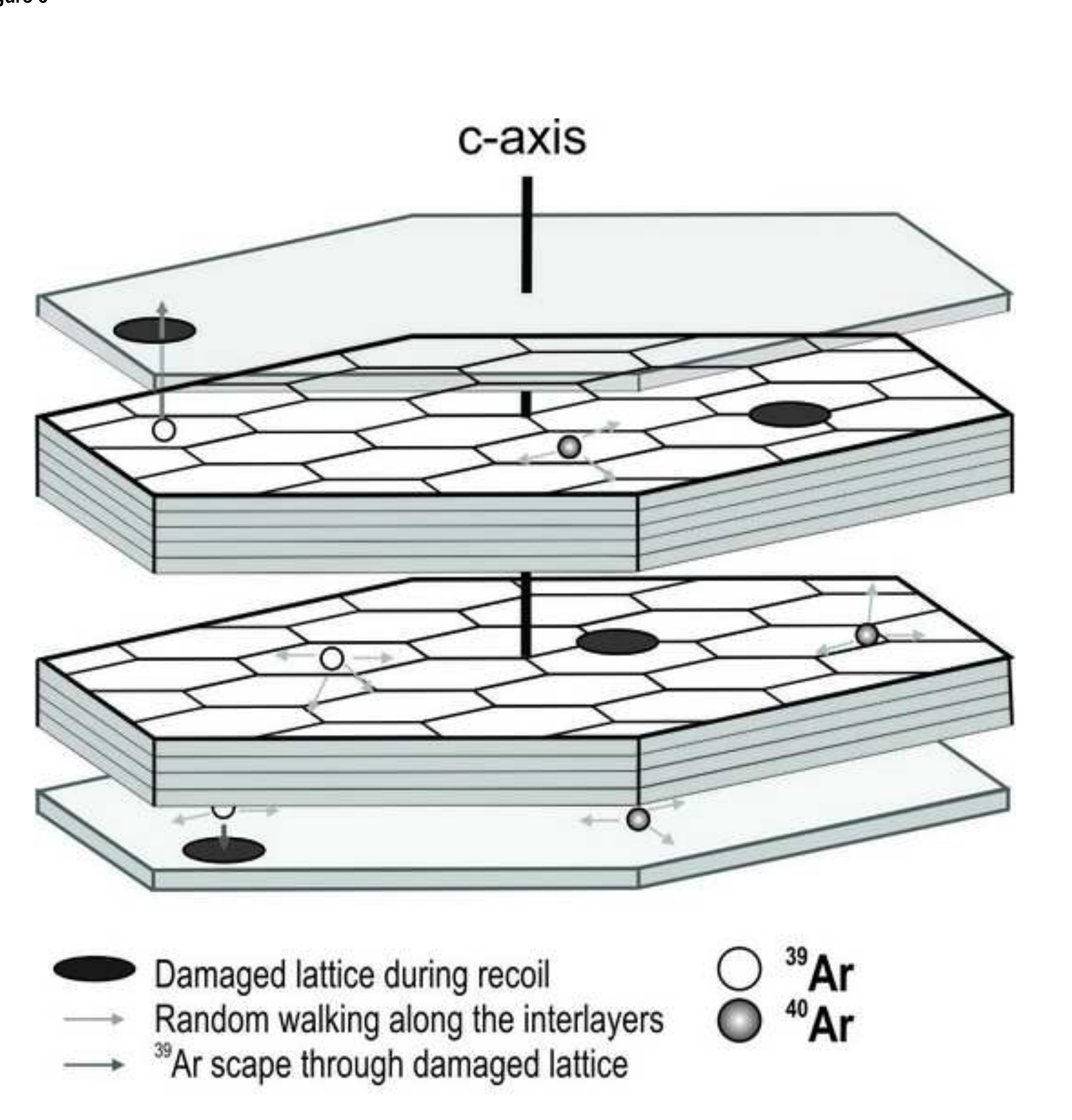

Figure 6

\section{c-axis}

Damaged lattice during recoil

Random walking along the interlayers

${ }^{9} \mathrm{Ar}$ scape through damaged lattice

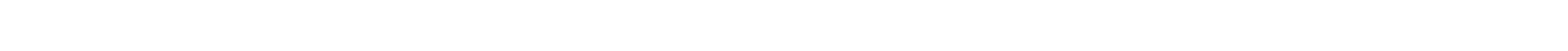
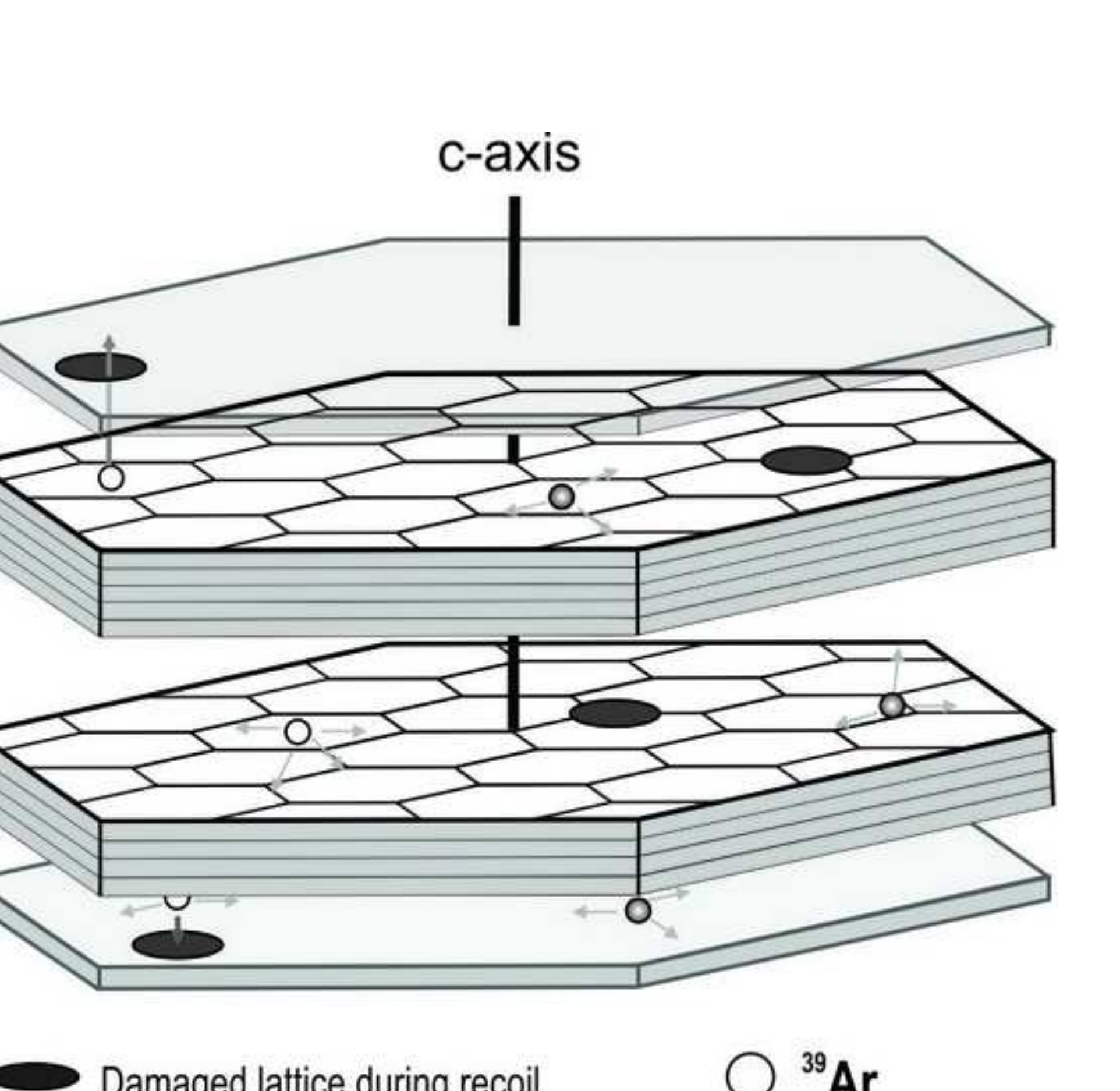

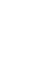

\section{Figure 6}

$$
\text { Figure } 6
$$



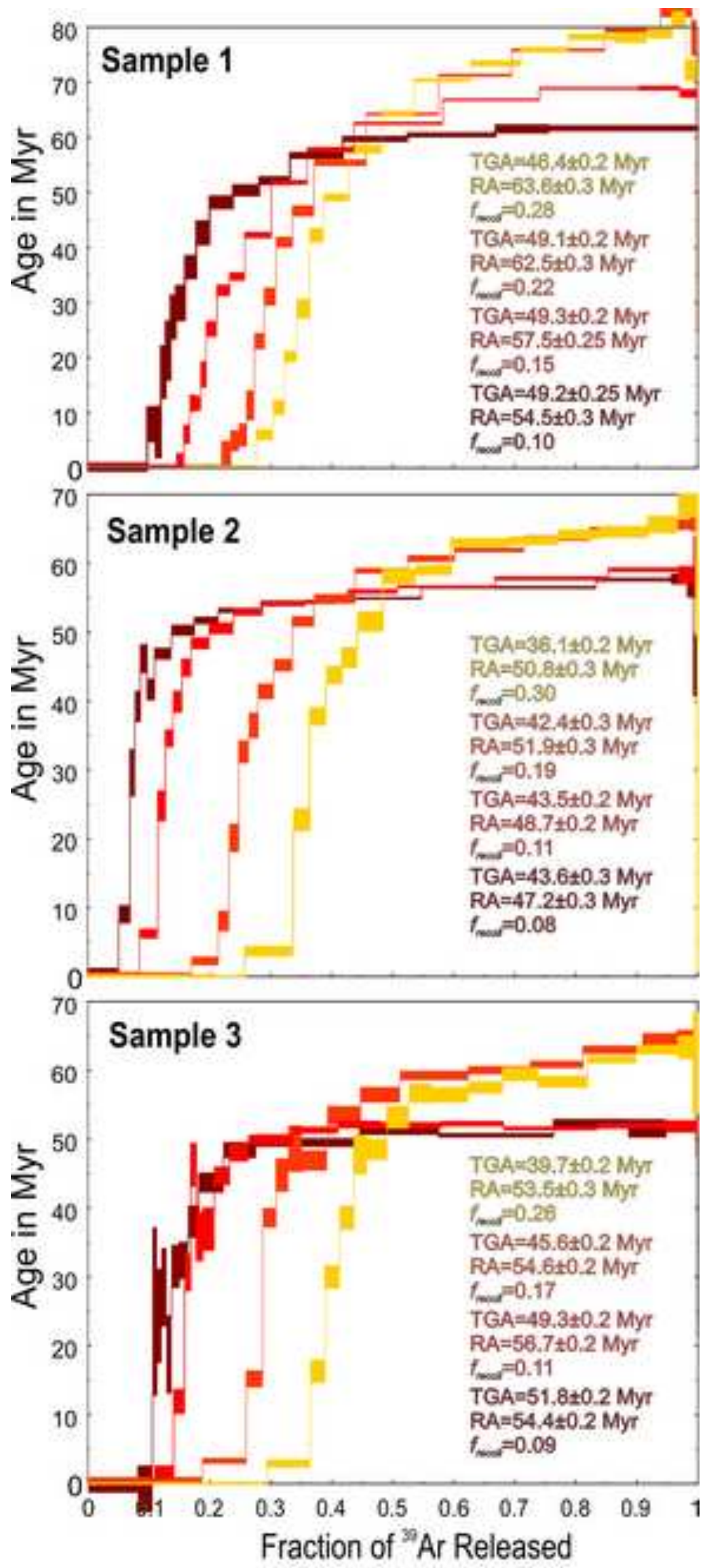

Figure 7 

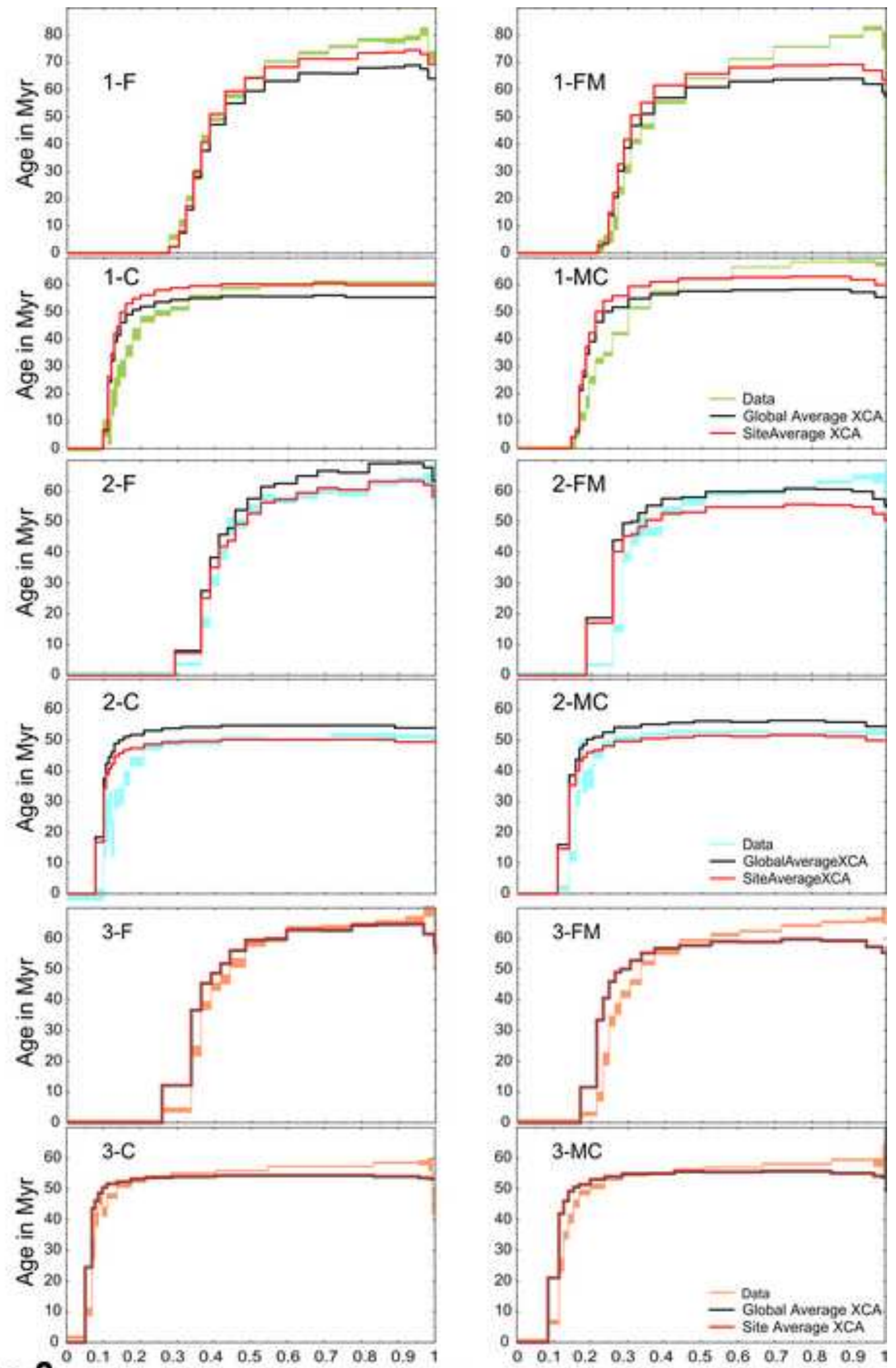

Figure 8 
Figure 9
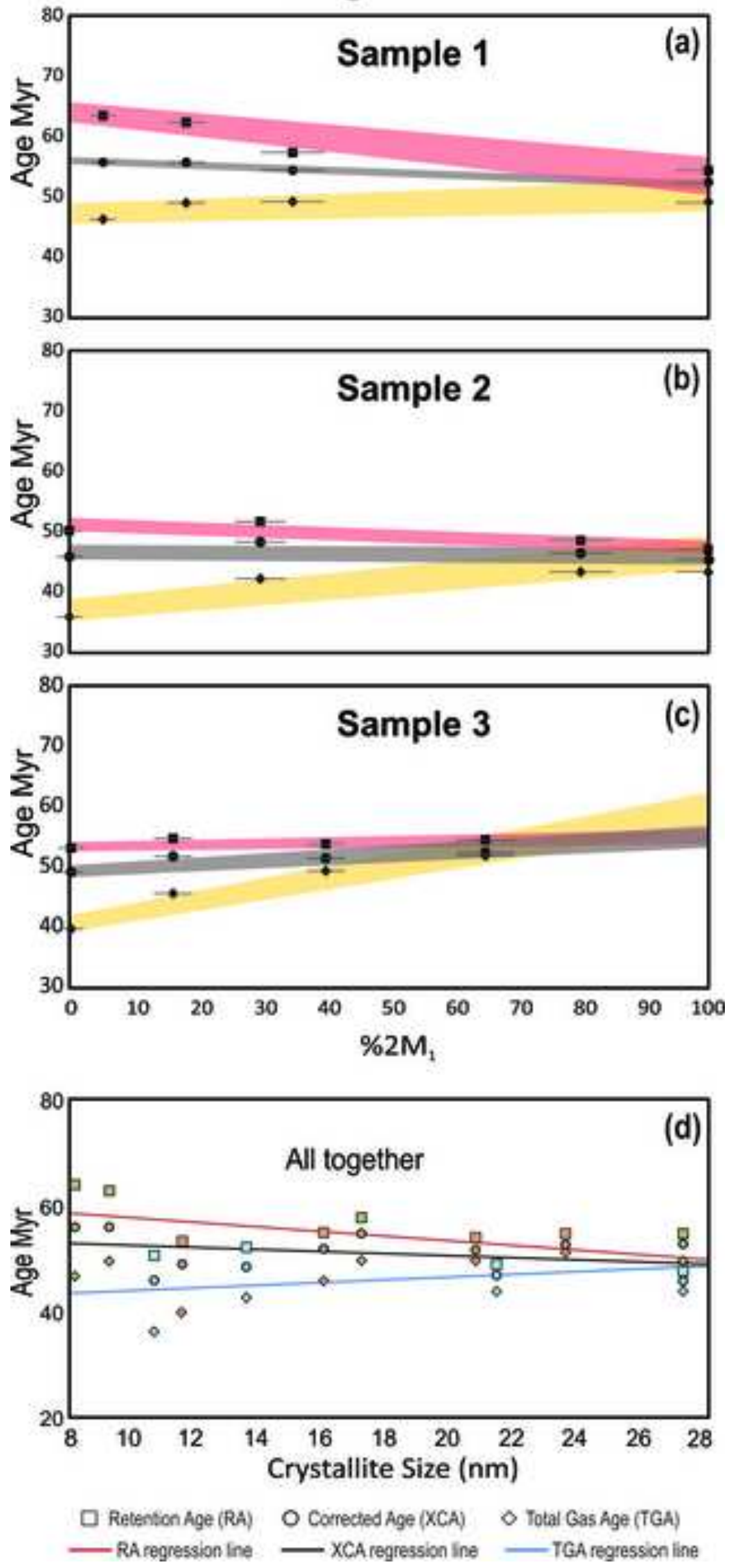


\title{
Appendix

\section{Appendix}

\begin{abstract}
Appox
\end{abstract}

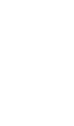

.
-

-

a 列 .
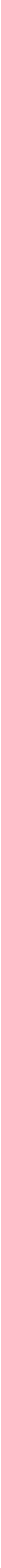

(1) 